\title{
Blast enhancement from metalized explosives
}

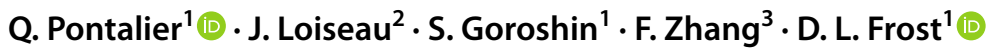

Received: 27 May 2020 / Revised: 10 December 2020 / Accepted: 13 December 2020 / Published online: 5 May 2021

(c) The Author(s) 2021

\begin{abstract}
Experiments are carried out to determine the effects of particle size and mass loading on the free-field blast wave from spherical, constant volume metalized explosive charges. The charges are comprised of gelled nitromethane with uniformly embedded aluminum, magnesium, or glass particles. Particle sizes are varied over an order of magnitude with particle mass fractions up to $50 \%$. Peak blast overpressures are directly measured within the fireball with piezoelectric pressure gauges and outside the fireball are inferred by tracking the velocity of the blast wave and using the Rankine-Hugoniot relation. With the addition of inert particles, the peak blast overpressure is initially mitigated, but then recovers in the far field. For charges with reactive particles, the particles react promptly with oxidizers in the detonation products and release energy as early as within the first few hundred microseconds in all cases. The particle energy release enhances the peak blast overpressures in the far field by up to twice the values for a constant volume charge of the baseline homogenous explosive. By plotting the peak blast overpressure decay as a function of energy-scaled distance, it is inferred that at least half of the particle energy release contributes to the blast overpressure in the far field of higher mass loadings, and nearly all of the particle energy for a particle mass fraction of $10 \%$. For aluminum, the blast augmentation is not a systematic function of particle size. This observation implies that conventional models for particle combustion that depend on particle surface area are not appropriate for describing the rapid aluminum reaction that occurs in the extreme conditions within the detonation products, which influences the blast wave propagation.
\end{abstract}

Keywords Blast wave enhancement $\cdot \mathrm{Al} / \mathrm{Mg}$ particles $\cdot$ Reaction timescales $\cdot$ Particle-blast interaction $\cdot$ Mass fraction . Particle size

\section{Introduction}

Communicated by D. Ranjan.

Supplementary Information The online version contains supplementary material available at https://doi.org/10.1007/s00193-021-00994-z.

Q. Pontalier

quentin.pontalier@mail.mcgill.ca

D. L. Frost

david.frost@mcgill.ca

1 McGill University, Macdonald Engineering Building, 817 Sherbrooke Street West, Montreal, QC H3A 0C3, Canada

2 Chemistry and Chemical Engineering Department, Royal Military College, 17 General Crerar Crescent, Kingston, ON K7K 7B4, Canada

3 Defence Research and Development Canada (DRDC) - Suffield, PO Box 4000, Stn Main, Medicine Hat, AB T1A 8K6, Canada
The addition of metallic particles to explosive formulations has been a common technique for enhancing the performance of conventional high explosives for over a century, going back to the study in 1899 by Escales [1] and the patent by Roth [2] in 1900. Blast enhancement studies with metalized explosives are based upon the fact that the volumetric energy release from metal reactions is generally larger than the base explosive itself, and the assumption that particle reaction may occur sufficiently rapidly to enhance the blast wave strength. It is assumed that for a constant volume charge, the energy release from the metal reaction more than compensates for the reduction in explosive mass with the particle addition, so that the overall energy output and, in turn, the blast strength are augmented.

Various reactive metals, such as aluminum, boron, magnesium, titanium, tungsten, and zirconium [3], have been added to explosives to enhance their performance. Aluminum is 
the most common metal used, due to the high heat of formation of condensed aluminum oxide, low metal density, and relatively low cost. Energy release from the oxidation of the added metal particles can increase the blast overpressure and impulse, and hence such metalized explosives are often referred to as enhanced blast explosives (EBX). Comprehensive reviews of such explosives have been prepared by Frost and Zhang [4], Trzciński and Maiz [5], and Türker [6]. The so-called combined effects aluminized explosives (see [7] for a specific review) are formulated to enhance their metal pushing performance as well as blast effects [8].

The addition of particles to an explosive influences the pressure history behind the blast wave produced in several ways. For inert particles, as they are accelerated by the expanding combustion products, and subsequently decelerate, the particles exchange momentum with the surrounding gas and perturb the local pressure field non-uniformly as the particles typically form particle jets or filaments [9]. This effect leads to a reduction in peak blast overpressure in the near field as the particles accelerate and to a corresponding augmentation farther from the charge as the particles decelerate and return energy to the flow [10-13]. In the case of reactive particles, the contribution of the energy release from the particle reaction to the local pressure field is more complex. The coupling between the particle reaction and the blast wave pressure depends on the heat transfer rate between the particles and the surrounding gas [14], the oxidizing species present [15], the reaction rate of the particles, and the location of the energy deposition [16]. Other phenomena that may influence the strength of the blast wave from a metalized explosive include afterburning of the explosive detonation products $[17,18]$ or afterburning of the reactive gases generated by particle combustion. Secondary fragmentation of partially reacted particles due to relative flow, the interaction of reflected waves, or impact with nearby structure may also contribute to the blast overpressure augmentation.

Even after more than a century of research, the physical mechanisms associated with the particle reaction and the augmentation of the blast pressure remain poorly understood. One of the main outstanding issues for aluminized explosives is quantifying the fraction of the energy release from the aluminum reaction that occurs on the timescale of the detonation propagation (i.e., on the order of microseconds), relative to the fraction that occurs on the timescale of the blast wave propagation (i.e., on the order of milliseconds). From research into the propagation of detonations in metalized explosives, or the so-called detonics regime, there is a growing body of evidence that metal particles can react on microsecond timescales behind the detonation wave and contribute to the ability to accelerate a metal casing [19-28]. The early signs of metal reaction seem to appear regardless of the explosive formulations used. In particular, metallic particles were observed to react at microsecond timescales in RDX [19-21], RDX-ammonium perchlorate (AP) [22], HMX [23, 24], nitroguanidine (NG), and bis(2,2,2-trinitroethyl)nitramine (BTNEN) [24]. Early-time contribution of $\mathrm{Al}$ reaction was also observed in hydrogen-free compounds such as benzotrifuroxan (BTN) [25], carbon-free substances such as ammonium nitrate (AN) [26], or liquids such as nitromethane (NM) [27-29]. For example, Loiseau et al. [28] measured the ability of mixtures of aluminum with gelled NM to accelerate a flyer plate. They found, for aluminum particles from 3.5 to $55 \mu \mathrm{m}$ in diameter, that the detonation products delivered more energy to the flyer plate than the baseline explosive within 1-3 $\mu$ s and concluded that the aluminum reaction begins very close to the detonation sonic plane. In mixtures of NM and packed beds of aluminum particles, Kato et al. [29] observed a detonation pressure increase due to $\mathrm{Al}$ reaction about $2.5 \mu$ sehind the leading shock for $8-\mu \mathrm{m} \mathrm{Al}$ particles. Additional evidence that aluminum can react promptly is given by recent experimental results that a mixture consisting of fine aluminum particles mixed with water (with $10 \%$ added hydrogen peroxide) can support the propagation of a detonation wave [30,31]. This implies that aluminum powder must be capable of reacting with water on a microsecond timescale to ensure that the propagation of the detonation front is self-sustained. Since the oxidizers present in the detonation products of common CHNO explosives consist primarily of water, with smaller amounts of carbon dioxide and carbon monoxide present, it is reasonable to assume that aluminum can react with the water in the products at the extreme conditions behind the detonation front or during the early stages of product expansion. Despite the evidence that aluminum can react on a microsecond timescale within detonation products, previous models for the propagation of blast waves from aluminized explosives have largely ignored this observation. Within the blast and shock wave community, it is often assumed that no particle reaction occurs during the detonics stage, and the particles then react with the combustion products and surrounding air on millisecond timescales, with the reaction rate assumed based on the wealth of single-particle combustion experimental results available at relatively low pressure and quiescent conditions; for example, see the particle reaction time correlations of Beckstead [32].

Particle sizes used in aluminized explosives have ranged over four orders of magnitude, from hundreds of nanometers to millimeters. Although nanometric aluminum particles were expected to react more rapidly than larger particles and contribute significantly to the blast strength, the predicted improvement in blast performance with adding nanoaluminum powder to an explosive has largely not been realized. Contributing factors to this include the difficulties in deagglomerating and dispersing nanopowder uniformly within an explosive, and the lower active aluminum content of the powder relative to larger particles due to the preexisting oxide layer which represents a 
larger fraction of the overall mass. For particles in the micrometric range (e.g., 1-200 $\mu \mathrm{m}$ ), previous studies showed little dependence of the particle size on the blast enhancement [15, $33,34]$. This is not consistent with most existing particle reaction models in which the reaction rate is determined by the amount of particle surface area available for reaction. We will return to this issue of the lack of dependence of particle size on blast performance and the implications for the particle reaction mechanism later in the Sect. 5.

Another parameter that influences the blast performance of aluminized explosives is the particle mass loading. As metal particles are mixed into an explosive, the explosive is diluted, reducing the mass fraction of explosive in the charge. However, the energy release from the reaction of the metal particles, which is larger on a volumetric basis than that of the explosive itself, partially compensates for the dilution effect. If the particle mass fraction is maximized, two other factors come into play. First, the resulting heterogeneous explosive will be highly fuel-rich and there will be insufficient oxidizer in the detonation products to fully react the metal. Secondly, the heat loss to the metal particles will reduce the temperature of the products and may inhibit or prevent the reaction of the particles altogether. In an earlier extensive series of experiments with packed beds of metal particles saturated with the liquid explosive-sensitized nitromethane (the solid mass fraction varied from 76 to $80 \%$, for aluminum particles larger than $8 \mu \mathrm{m}$ ), we observed a range of different particle reaction behaviors and blast effects, depending on the particle and charge size [4]. In many cases, the particles did not fully react, making it difficult to systematically determine the influence of particle size and mass loading on the blast enhancement from the metal particles. Similar effects were also observed by Trzciński and Maiz [5] for fully dense nitromethane-particle mixtures.

In addition to the particle mass loading, another parameter that strongly influences the blast performance from metalized explosives is the scale of the charge, which governs the residence time of the particles within the hot detonation products before expansion cooling of the products may quench further particle reaction. From experimental results with $\mathrm{kg}$-scale charges containing packed beds of magnesium particles saturated with nitromethane, a critical charge size for particle reaction was clearly observed, which depends on particle size [35]. The particle reaction behavior and blast wave parameters will not be preserved with a change in scale. The importance of considering the scale in interpreting results regarding the effect of particle size on blast enhancement in aluminized explosives has been pointed out by Peuker et al. [15] who carried out experiments with subgram quantities of aluminized explosive.

The trade-off between dilution and enhanced energy density effects with the addition of particles suggests a critical mass fraction should exist that optimizes the explosive blast performance. The optimum mass fraction will depend on the type of reactive particle used as well as the nature of the explosive and is best determined experimentally. To find the optimum particle mass loading with the nitromethane-particle system, it is necessary to gel the NM to enable the suspension of the particles. This technique was used by Loiseau et al. [28] and Trzciński et al. [36], who carried out experimental studies in which nitromethane was gelled with the addition of $4 \mathrm{wt} \%$ PMMA to allow a reduction in the particle loading. Trzciński et al. [36] investigated the effect of adding different fractions (15-60 wt\%) of an Al-Mg alloy on the detonation properties and blast wave properties in a confined area from $200 \mathrm{~g}$ cylindrical charges. The highest peak overpressure and impulse values at $2 \mathrm{~m}$ from the charge were found for explosives with a particle mass fraction of $30 \%$. The mean particle size was $63 \mu \mathrm{m}$.

In the present study, gelled nitromethane is also used as the base explosive, with various mass fractions of aluminum, magnesium, or glass particles added. Of particular interest is the effect of varying the particle size as well as the mass fraction on the blast wave properties. The motivation of the work is to determine if the rapid (sub-millisecond timescale) reaction of aluminum in detonation products that has been observed in earlier detonics experiments can be shown experimentally to directly contribute to blast wave performance for charges with a prototypical scale ( $\mathrm{kg}$ quantities) and a particle mass loading in a range that ensures uniform reaction of the particles. In the following sections, the experiments will first be described (Sect. 2), followed by a description of the pressure gauge analysis and video data reduction procedure (Sect. 3). Presentation and discussion of the experimental results are given, respectively, in Sects. 4 and 5 before the conclusions (Sect. 6). Additional results are given in the Appendix.

\section{Experimental overview}

The baseline explosive charge utilized a thin-walled G40 light bulb for a casing ( $1 \mathrm{~mm}$ thickness and nominal diameter of $12.7 \mathrm{~cm}$ ), with the filament removed and filled with nitromethane (NM). The NM was gelled to the consistency of liquid honey to suspend the particles by adding $4 \mathrm{wt} \%$ polymethyl methacrylate (PMMA), with $0.4 \mathrm{wt} \%$ of $3 \mathrm{M} \mathrm{K} 1$ glass microballoons (GMBs) added to sensitize the mixture. This explosive mixture was previously used in another study [28]. Various sized spherical aluminum powders (H-10, $13 \mu \mathrm{m}$ dia.; H-50, $54 \mu \mathrm{m}$ dia.; H-95, $114 \mu \mathrm{m}$ dia.; Valimet, Stockton, CA) were added at mass fractions ranging from 10 to $50 \%$. Since the charge volume was constant at about $1 \mathrm{~L}$, the fraction of gelled $\mathrm{NM}$, as well as the $\mathrm{Al}$ mass fraction, varied between trials. Tests were also carried out with spherical glass particles (+325/- 170 mesh; $66 \mu \mathrm{m}$ 
dia.) to serve as a non-reactive particle case for comparison, as well as a limited number of trials using spherical $\mathrm{Mg}$ powder (GRAN 17, $240 \mu \mathrm{m}$ dia.; Reade, PA). The charges were detonated by inserting a detonator (Reynolds RP-83) into a booster charge of 85.7-92.7 $\mathrm{g}$ (depending on the trial, see trial matrix in Table 1) of C-4 formed by hand, placed within a plastic sphere and held in place at the center of the charge with a glass tube through which the detonator was inserted. The charge was placed on the top of a wooden post, with a height of burst of $1.52 \mathrm{~m}(\mathrm{HOB} \approx 12$ times the charge diameter). For each trial, the blast overpressure was recorded with three fast-response ( $1.5 \mu$ s rise time) piezoelectric pressure transducers mounted in lollipop-style gauges (dia. $30 \mathrm{~cm}$ ). The transducers were located at $1.0 \mathrm{~m}$ (PCB 113B26/PCB 113A31 depending of the trial), $1.5 \mathrm{~m}$ (PCB 113A31), and $2.0 \mathrm{~m}$ (PCB 113A31) from the charge, with the furthest gauge at almost $90^{\circ}$ as shown schematically in Fig. 1. The gauge at $2.0 \mathrm{~m}$ is also visible behind the charge in Fig. 2. The distance of this gauge from the charge was chosen such that the ground-reflected wave arrived at the transducer location after the end of the positive phase of the blast wave signature so that the blast overpressure profile was not influenced by the reflected wave.

The motion of the blast front was visualized using two Phantom v1610 high-speed video cameras recording at 16,000 frames/s (camera 1) and 35,000 frames/s (camera 2 ), respectively. The camera 1 operating at the slower speed had a higher resolution $(1280 \times 800$ pixels $)$ and was used for the analysis of the shock wave motion. This camera was offset to the left relative to the charge to provide the maximum field of view, as shown in Fig. $1\left(C^{\prime} E=1.67 \mathrm{~m}\right)$. The distance from the camera to the point $\mathrm{C}^{\prime}$ shown in Fig. 1 was $\mathrm{CC}^{\prime}=34.50 \mathrm{~m}$. The resulting absolute Euclidean distance from the camera to the charge was $\mathrm{CE}=34.54 \mathrm{~m}$. To enhance the visualization of the blast front, a zebra board (width of stripes is about $15 \mathrm{~cm}$ ) was placed behind the charge at a distance of $C^{\prime} Z=5.00 \mathrm{~m}$, resulting in a distance of $\mathrm{CZ}=39.50 \mathrm{~m}$ between the camera and the backdrop. The camera was focused on the plane of the charge center. Using the two black fiducial markers on the backdrop (shown in Fig. 2), spaced $3.95 \mathrm{~m}$ apart, for scaling, and with the camera resolution, the physical size of one pixel in the plane of the backdrop is estimated to be $3.7 \mathrm{~mm}$. The corresponding size of a pixel in the plane of the charge is calculated to be $3.2 \mathrm{~mm}\left(=3.7 \times \frac{\mathrm{CC}^{\prime}}{\mathrm{CZ}}\right)$. This value multiplied by the blast radius measured in pixels gives the value $R_{\text {app }}$. For all the trials, to increase again the field of view, the camera was rotated slightly to the left so that the charge center was just out of view to the right. Since the rotation angle is relatively small $\left(\approx 0.4^{\circ}\right)$, the value of $R_{\text {app }}$ is not expected to vary significantly and, consequently, no additional correction has been applied. Camera 2 was set to a resolution of $1152 \times 400$ pixels and was placed adjacent to camera 1 slightly to the right as shown in Fig. 1. This camera was used exclusively for the qualitative analysis of the fireball structures in Sect. 4.1. Contrary to camera 1, the charge is

Table 1 Trial matrix

\begin{tabular}{|c|c|c|c|c|c|c|c|}
\hline Trial & Material & $\mathrm{wt} \%$ & Mean particle size $(\mu \mathrm{m})$ & $\mathrm{C} 4$ booster mass $(\mathrm{g})$ & Mass mixture (g) & $P_{0}(\mathrm{kPa})$ & $T_{0}\left({ }^{\circ} \mathrm{C}\right)$ \\
\hline$\# 0$ & Baseline & - & - & 87.2 & 979.2 & 92.79 & 24 \\
\hline \#1 & $\mathrm{H}-10 \mathrm{Al}$ & 10 & 13 & 88.9 & 1039.8 & 93.12 & 26 \\
\hline$\# 2$ & $\mathrm{H}-10 \mathrm{Al}$ & 30 & 13 & 92.2 & 1183.5 & 92.71 & 26 \\
\hline$\# 3$ & $\mathrm{H}-10 \mathrm{Al}$ & 40 & 13 & 91.3 & 1257 & 93.59 & 26 \\
\hline \#4 & $\mathrm{H}-50 \mathrm{Al}$ & 10 & 54 & 87.6 & 1035.3 & 92.96 & 25 \\
\hline$\# 5$ & $\mathrm{H}-50 \mathrm{Al}$ & 20 & 54 & 90.8 & 1106.4 & 92.79 & 24 \\
\hline \#6 & $\mathrm{H}-50 \mathrm{Al}$ & 30 & 54 & 88.89 & 1179.5 & 92.89 & 25 \\
\hline \#7 & H-50 Al & 40 & 54 & 87.7 & 1281.3 & 93.67 & 22 \\
\hline$\# 8$ & $\mathrm{H}-50 \mathrm{Al}$ & 40 & 54 & 86 & 1303.4 & 92.96 & 25 \\
\hline$\# 9$ & $\mathrm{H}-95 \mathrm{Al}$ & 10 & 114 & 90 & 1044.6 & 93.19 & 25 \\
\hline \#10 & $\mathrm{H}-95 \mathrm{Al}$ & 30 & 114 & 85.7 & 1175.4 & 92.76 & 26 \\
\hline \#11 & H-95 Al & 40 & 114 & 92.2 & 1298.5 & 93.7 & 25 \\
\hline$\# 12$ & $\mathrm{H}-95 \mathrm{Al}$ & 50 & 114 & 87.7 & 1407 & 93.2 & 26 \\
\hline$\# 13$ & Gran $17 \mathrm{Mg}$ & 10 & 240 & 86 & 1024.6 & 92.94 & 21 \\
\hline \#14 & Gran $17 \mathrm{Mg}$ & 20 & 240 & 91.7 & 1051.8 & 93.75 & 24 \\
\hline \#15 & Gran $17 \mathrm{Mg}$ & 30 & 240 & 88.8 & 1085.7 & 92.92 & 23 \\
\hline$\# 16$ & Gran $17 \mathrm{Mg}$ & 40 & 240 & 88.6 & 1140.7 & 93.83 & 21 \\
\hline$\# 17$ & Glass beads & 10 & 66 & 92.7 & 1038.5 & 93.21 & 23 \\
\hline \#18 & Glass beads & 30 & 66 & 87.4 & 1169.9 & 92.75 & 22 \\
\hline \#19 & Glass beads & 50 & 66 & 87.3 & 1378.5 & 93.19 & 22 \\
\hline
\end{tabular}

The baseline corresponds to the gelled NM (95.6 wt $\% \mathrm{NM}+0.4 \mathrm{wt} \% \mathrm{GMB}+4 \mathrm{wt} \% \mathrm{PMMA}) . P_{0}$ and $T_{0}$ correspond, respectively, to the atmospheric pressure and temperature 


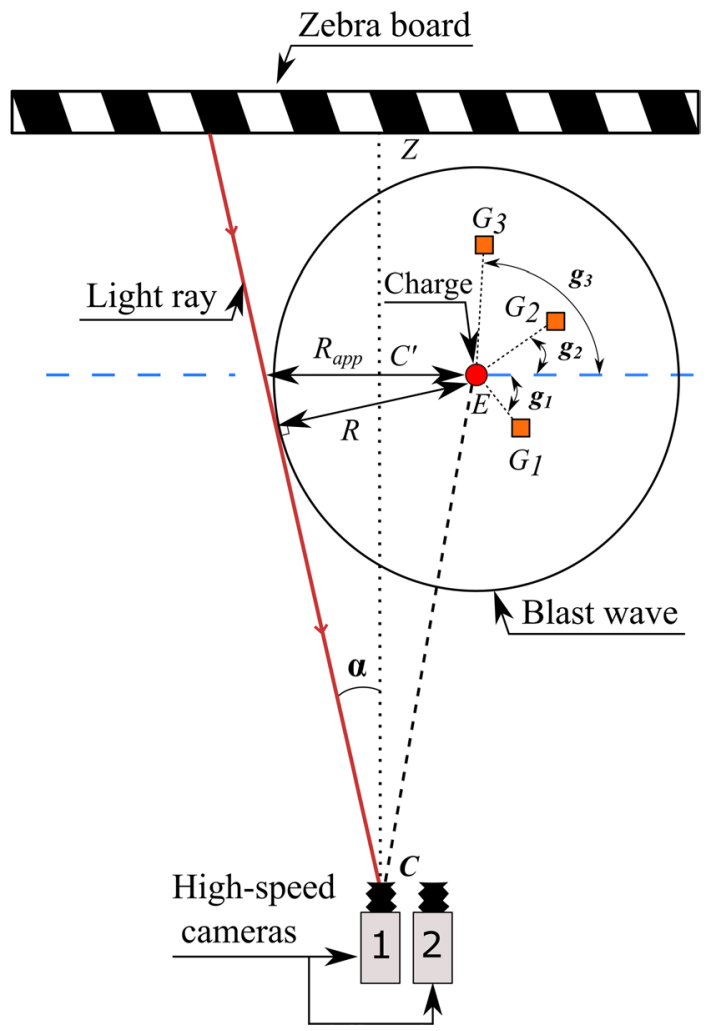

Fig. 1 Experimental overview (top view). The cameras were focused on the charge plane (dashed blue line). When the blast is viewed through a certain angle $(\alpha)$, the apparent blast radius $\left(R_{\text {app }}\right)$ overestimates the actual blast radius $(R)$. The optical axis of the camera $1(\mathrm{CZ})$ is quasi-perpendicular to the charge plane. The pressure gauges denoted G1 $\left(\varangle g_{1}=54.1^{\circ}\right), \mathrm{G} 2\left(\varangle g_{2}=53.8^{\circ}\right)$, and G3 $\left(\varangle g_{3}=88.4^{\circ}\right)$ are located, respectively, EG1 $=1.0 \mathrm{~m}, \mathrm{EG} 2=1.5 \mathrm{~m}$, and EG3 $=2.0 \mathrm{~m}$ from the charge. Camera 2 was only used to visualize the fireball structures (Sect. 4.1)

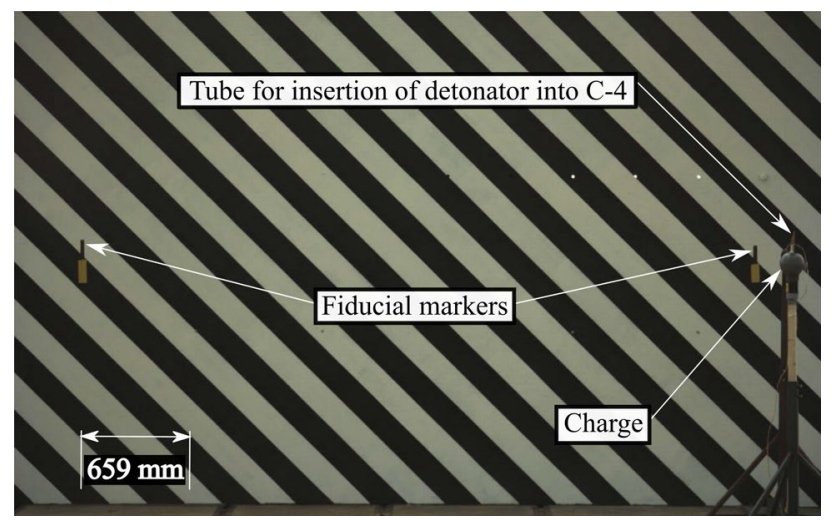

Fig. 2 Photograph of the experimental setup with zebra board backdrop (front view). The scale shown is in the plane of the zebra board

in the field of view of camera 2. In total, 20 trials were conducted with, respectively, 1 trial with the baseline charge (95.6 wt\% gelled NM + $4 \mathrm{wt} \%$ PMMA + $0.4 \mathrm{wt} \%$ GMB),
12 trials conducted with added aluminum powder ( 3 with $\mathrm{H}-10 \mathrm{Al}, 5$ with $\mathrm{H}-50 \mathrm{Al}, 4$ with $\mathrm{H}-95 \mathrm{Al}), 4$ with magnesium powder (GRAN $17 \mathrm{Mg}$ ), and 3 trials conducted with added spherical glass beads. A summary of the trials conducted is presented in Table 1, and the videos of selected trials are available online as supplementary materials.

\section{Analysis methodology}

In this section, the different methods for extracting the blast properties are described. Since the blast properties may depend on the actual distance from the charge, to avoid confusion with the terminology, we denote the near field as the region up to $2 \mathrm{~m}$ from the charge, the mid-field region $2-3 \mathrm{~m}$ from the charge, and the far-field region beyond $3 \mathrm{~m}$ from the charge.

\subsection{Blast overpressure profiles from pressure gauges}

The pressure-time histories were recorded by three transducers placed at $1.0 \mathrm{~m}, 1.5 \mathrm{~m}$, and $2.0 \mathrm{~m}$ from the charge. The transducers were located close enough to the charge that in most cases they were engulfed by the fireball, with the farthest transducer (at $2 \mathrm{~m}$ from the charge) typically near the maximum extent of the fireball. The non-uniform density field within the fireball, which is manifested by the conical jets that are visible projecting out of the fireball interface, leads to fluctuations in the pressure signals. Misalignment of the face of the lollipop gauge with the direction of travel of the blast wave can also generate expansion waves from the edge of the lollipop, which influences the pressure recorded shortly after the pressure reaches a maximum. An example of the overpressure history (i.e., the pressure above atmospheric pressure, $\Delta P=P-P_{0}$ ) recorded at $2.0 \mathrm{~m}$ from the charge is shown in Fig. 3 for the trial with the charge containing $30 \mathrm{wt} \%$ of $\mathrm{H}-50 \mathrm{Al}$. The peak blast overpressure $\left(\Delta P_{\mathrm{s}}\right)$ corresponds to the maximum overpressure value. Values of all peak overpressures at $2.0 \mathrm{~m}$ from the charge are included in the Appendix (Tables 5 and 6). The blast time of arrival corresponds to the time separating the beginning of the oscillatory signal generated by the burst of the detonator (exactly correlated with time zero in Fig. 3) and the time of the maximum overpressure. Note that the previous definitions may introduce error in the estimation of the peak blast overpressure and blast arrival times, especially if the blast front is not associated with the maximum recorded overpressure. This scenario may happen if the gauges are misaligned with the direction of propagation of the blast wave. Both the secondary shock and the ground-reflected wave are evident on the pressure signal. The timing of the arrival of the ground-reflected shock can 


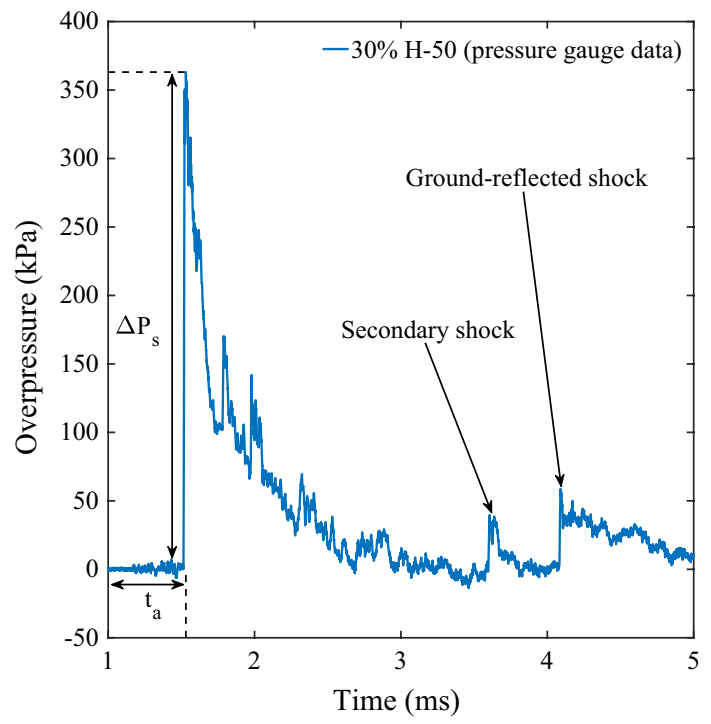

Fig. 3 Overpressure profile captured at $2.0 \mathrm{~m}$ from the charge in the case of a charge containing H-50 aluminum at a mass fraction of $30 \%$ (trial \#6)

also be determined from the high-speed videos. The gauge located at $2.0 \mathrm{~m}$ is closest to the zebra board, although the reflected wave from the zebra board arrives at the gauge after a delay of $13.83 \mathrm{~ms}$, which is not visible on the signal shown. The pressure profiles recorded within the fireball (at $1.0 \mathrm{~m}$ and $1.5 \mathrm{~m}$ from the charge) differ substantially from that of the (modified) Friedlander form [37], making it difficult to determine unambiguous values for the blast duration and peak overpressure. As a consequence, the trial-by-trial comparison of peak overpressure data is not considered at these distances. However, the blast times of arrival at 1.0 $\mathrm{m}$ are analyzed globally to evaluate the shortest aluminum reaction timescales. Due to the oscillatory nature of the pressure signal and the difficulty in choosing an unambiguous positive-phase blast duration, the calculated impulse values are not analyzed further.

\subsection{Video analysis}

The blast front trajectories were determined through analysis of the high-speed videography images. To enhance the visibility of the blast wave, the function find edges was applied to the images using the open-source image processing software ImageJ. Since the vertical motion of the blast wave is perturbed by the flow of detonation products out of the tube holding the detonator, the blast front is tracked along a horizontal line emanating from the charge center. As the location of the blast front extracted from the images $\left(R_{\text {app }}\right)$ overestimates the actual location $(R)$ due to the parallax effect, a correction is implemented before calculating the blast velocity.

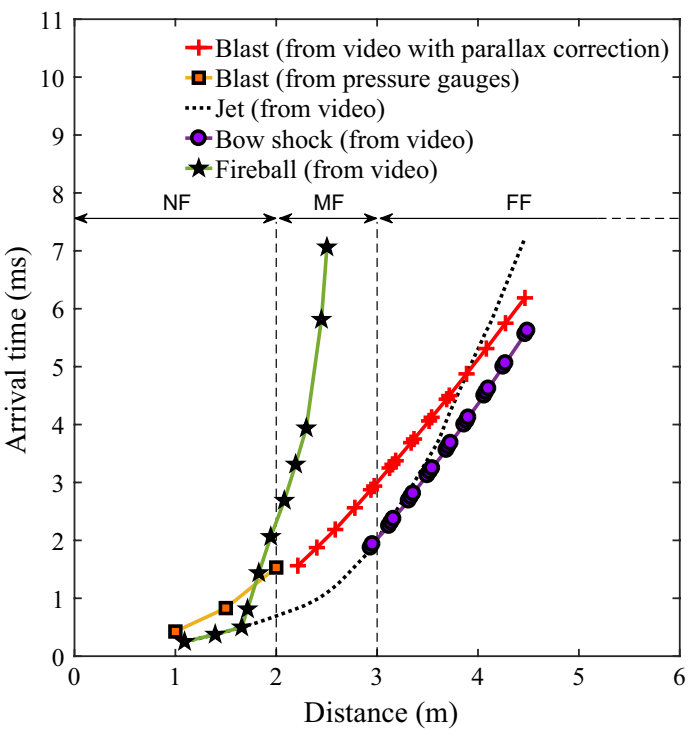

Fig. 4 Trajectories of the blast wave with the parallax correction for the case of a charge with $30 \mathrm{wt} \%$ of H-50 (trial \#6) aluminum particles. Also shown are the blast arrival times obtained from the three pressure transducers as well as the trajectory of the bow shock that is driven by a jet of particles that is projected ahead of the blast front. The approximate trajectory of the maximum extent of the fireball is also plotted. The abbreviations NF, MF, and FF correspond, respectively, to near field, mid field, and far field

The formula used to calculate the actual distance from the blast front to the charge center is given as follows:

$R=R_{\text {app }} \times \frac{\mathrm{CC}^{\prime}}{\sqrt{R_{\mathrm{app}}^{2}+\mathrm{CE}^{2}-2 \times R_{\mathrm{app}} \times \mathrm{C}^{\prime} \mathrm{E}}}$

where $R<R_{\text {app }}$ is generally excepted when $R=R_{\text {app }}=\mathrm{C}^{\prime} \mathrm{E}$. The blast trajectory with taking into account the parallax is plotted in Fig. 4. Note that the blast wave is not visible until it has propagated about $2 \mathrm{~m}$ due to the saturation of the video images from the luminosity of the fireball. Note also that data points are gathered by a group of 2 or 3, at regularly spaced intervals. These points are extracted when the blast front approaches the intersection of two consecutive stripes (shown in the background of Fig. 2), where the contrast is optimum. To determine the blast velocity, the blast trajectory is fitted by the monotonic fit of Kleine et al. [38] and then differentiated. The parallax correction is relatively small, with a typical error in the velocity of about $2 \%$ (4\% when converted into pressure), with the error highest when the blast wave is furthest from the charge. An approximate estimation of the trajectory of the maximum extent of the fireball is also plotted in Fig. 4. As mentioned previously, the first two gauges are engulfed in the fireball and the last gauge is typically very close to the contact surface. 
The peak blast overpressure can be extracted by using the blast wave Mach number together with the Rankine-Hugoniot relation, provided the local temperature and pressure are known. For each trial, the local temperature (ranging from 21 to $26^{\circ} \mathrm{C}$ ) and atmospheric pressure (ranging from 92.71 to $93.83 \mathrm{kPa}$ at an altitude of $700 \mathrm{~m}$ ) were recorded (see Table 1) and used in the Rankine-Hugoniot relations. Further details of the method of determining the peak blast overpressure in this way can be found in an earlier publication [10]. Since the direct visualization of the blast front on the tracking line is not generally possible for distances from the charge less than $2.0 \mathrm{~m}$, the peak blast overpressure is extrapolated in the near field by inferring the blast curvature, as shown in Fig. 5, for a direct comparison with gauge data. The results of this comparison are gathered in Table 7, in the Appendix.

When extracting the blast wave trajectories, care must be taken to distinguish the actual blast front from the localized pressure disturbances (or bow shocks) created by the jets that are formed during the explosive event, as illustrated in Fig. 6. Due to the white color of these jet-like structures, they likely are comprised of agglomerated aluminum oxide particles or perhaps partially reacted aluminum in the case of large initial solid mass loading. The bow shocks may be either ahead of or behind the blast front. Since the two features are not propagating at the same speed, one propagating in ambient air and the other in the post-shocked medium, they ultimately merge after some time. In Fig. 4, trajectories of the jet and the bow shock visible ahead of the blast front are plotted. Initially separated in space, the blast front and the bow shock tend to converge while propagating outward. On the contrary, the bow shocks tend to separate from the

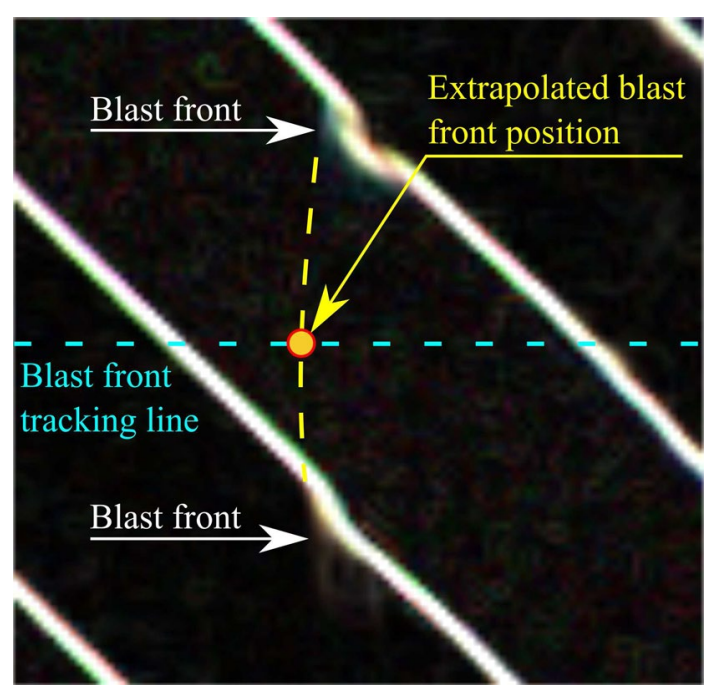

Fig. 5 Processed image with the find edges function showing the extrapolation method of the blast front in the near-to-mid field, on the blast front tracking line

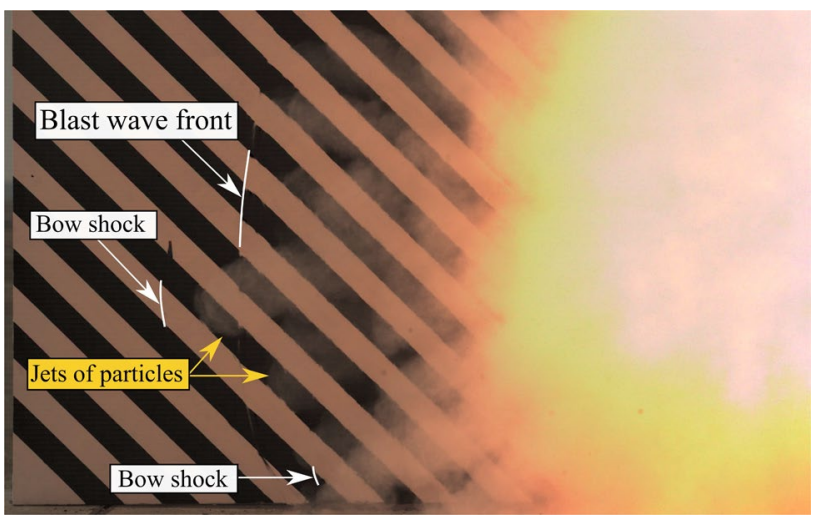

Fig. 6 Single frame from the video record of a test for a charge with $30 \mathrm{wt} \%$ of H-50 (trial \#6) aluminum particles illustrating shock tracking against zebra board

particle jets, due to aerodynamic drag with the surrounding atmosphere. The effect of the localized bow shocks on the peak blast overpressure has been discussed in previous publications $[10,11]$.

\section{Results}

\subsection{Visualization of fireball expansion and blast propagation}

To illustrate the dynamics of the fireball expansion and afterburning and the blast wave propagation, single frames from the video records of camera 2 have been extracted from a series of trials. Figure 7 shows the images for the detonation of the baseline gelled nitromethane explosive. After about $0.5 \mathrm{~ms}$, the fireball is highly luminous, but the processed image indicates that small-scale perturbations and jet-like structures are present on the fireball interface, likely due to action of the Rayleigh-Taylor (RT) instability. After $1 \mathrm{~ms}$, the expansion has cooled the fireball gases and the interface between the detonation products and surrounding atmosphere appears highly convoluted. The fireball continues to expand and cool until the secondary and the ground-reflected waves propagate up through the fireball, enhancing the mixing and afterburning of the products. The top interface of the highly luminous region in the image at $4 \mathrm{~ms}$ corresponds to the reflected wave that is propagating upward at this time.

Figure 8 shows the effect of adding $30 \mathrm{wt} \%$ of inert glass particles to the gelled nitromethane. The image taken at $0.314 \mathrm{~ms}$ shows the luminous fireball, and the processed image indicates that conical jet-like structures are present, perhaps caused by entrainment of the glass particles into the RT perturbations. Fine streaks of particles are also present in this image near the fireball interface, which may be from 
Fig. 7 Single frames from the video record of the detonation of a charge containing the baseline gelled nitromethane explosive (trial \#0). The images on the left are the original video images, and the images on the right are the same images, but after an edge Laplacian $5 \times 5$ filter has been applied to highlight the gradients in the image. Times for the image are (top to bottom): $0 \mathrm{~ms}, 0.514 \mathrm{~ms}$, $1.000 \mathrm{~ms}, 2.000 \mathrm{~ms}$, and 4.000 $\mathrm{ms}$, respectively. The arrows indicate the locations of the blast wave
Fig. 8 Single frames from the video record of the detonation of a charge containing 30 wt\% glass particles (trial \#18). Similar to Fig. 7, the images on the left are the original video images and the same images are on the right, after an edge Laplacian $5 \times 5$ filter has been applied to highlight the gradients in the image. Times for the image are (top to bottom): $0 \mathrm{~ms}$, $0.314 \mathrm{~ms}, 1.000 \mathrm{~ms}, 2.000 \mathrm{~ms}$, and $4.000 \mathrm{~ms}$, respectively. The arrows indicate the locations of the blast wave
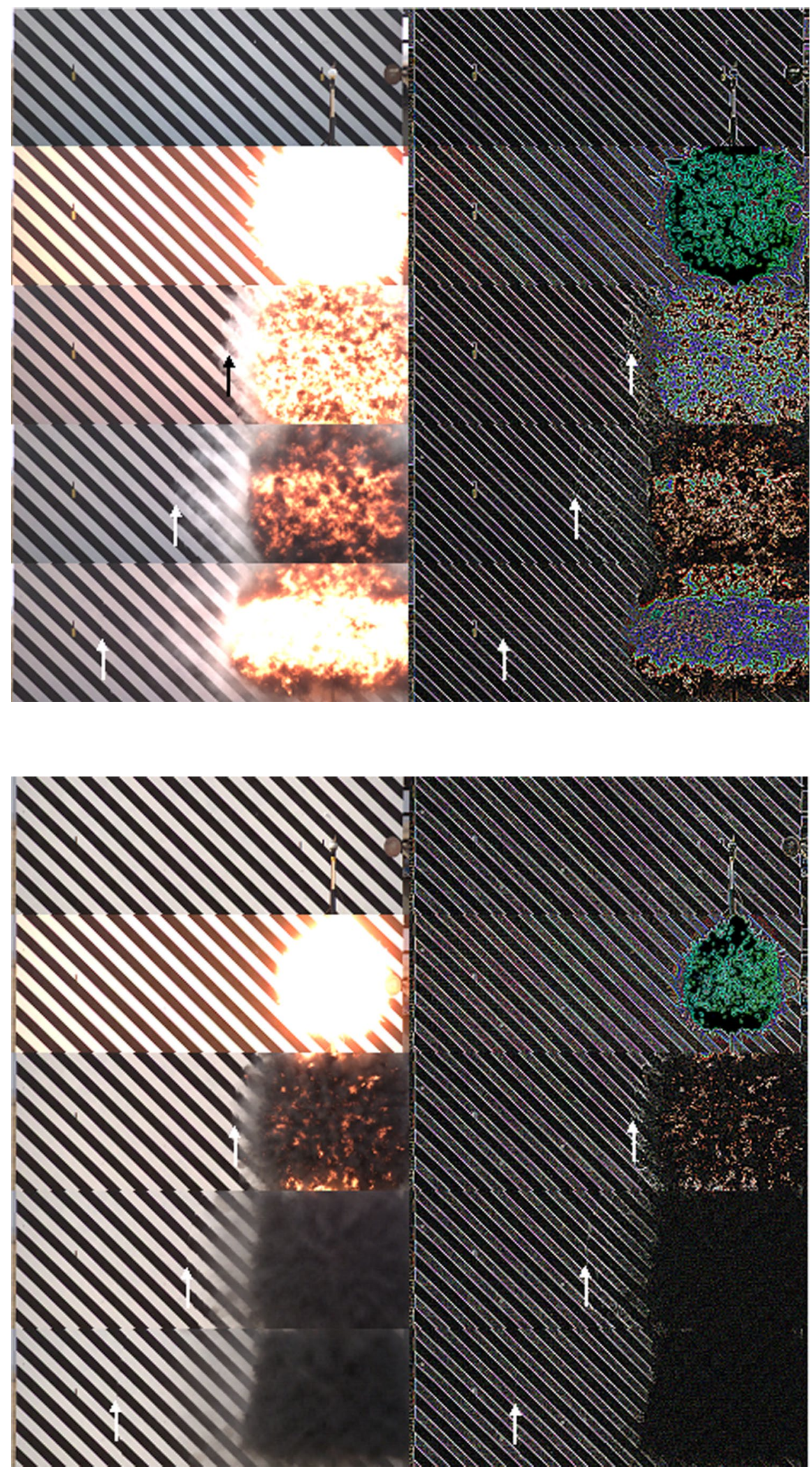
the motion of the fine glass particles from the shattering of the glass light bulb casing. At times of $1 \mathrm{~ms}$ and later, the fireball has expanded and cooled. The secondary and the ground-reflected waves do not induce significant afterburning of the soot from the NM products, due to the absorption of heat by the added inert glass.

Figure 9 illustrates the fireball afterburning and blast wave propagation in the case of a charge with $30 \mathrm{wt} \% \mathrm{H}-50 \mathrm{Al}$ particles. Prominent conical particle jets form and project ahead of the primary blast front, which is only visible emerging from the fireball interface mixing region after about $2 \mathrm{~ms}$. The fireball intensity does not diminish during the recording time of the video $(10 \mathrm{~ms})$, as the afterburning of the soot from the detonation products as well as energy release from the aluminum reaction continues to contribute to the fireball luminosity. The reader can refer to the videos available online for a dynamic visualization of Figs. 7, 8, and 9.

To illustrate the variation of luminosity between these three trials (\#0,\#6,\#18), the spatially averaged pixel intensity $(\mathscr{L})$ is defined as:

$\mathscr{L}=\frac{\sum_{i=1}^{i_{\max }} \sum_{j=1}^{j_{\max }} P_{i, j}}{N}$

with $i_{\max }=1280$, the number of pixels by width; $j_{\max }=$ 800 , the number of pixels by height; $N=i_{\max } \times j_{\max }=$ $1280 \times 800=1,024,000$, the total number of pixels in a

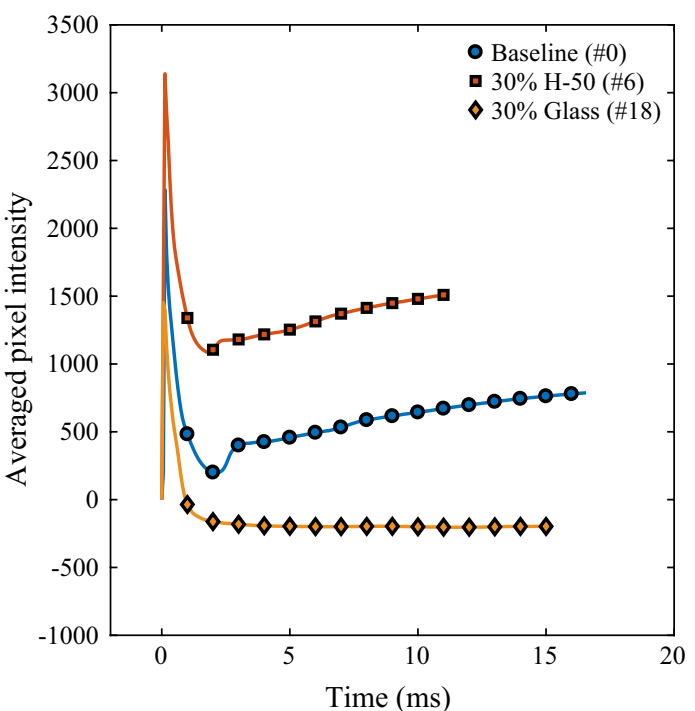

Fig. 10 Comparison of spatially-averaged pixel intensity $(\mathscr{L})$ as a function of time between the baseline explosive (trial \#0) and with mixtures with $30 \mathrm{wt} \% \mathrm{H}-50$ (trial \#6) and $30 \mathrm{wt} \%$ glass beads (trial \#18)

frame; and $P_{i, j}$, the intensity value of the pixel of coordinate $(i, j)$ from the original 16-bit cine (Phantom format) files, is plotted as a function of time, in Fig. 10. The cine file format is preferred to the RGB format to avoid correction of
Fig. 9 Single frames from the video record of the detonation of a charge containing $30 \mathrm{wt} \%$ $\mathrm{H}-50 \mathrm{Al}$ particles (trial \#6). As shown in Figs. 7 and 8, the images on the left are the original video images and the images on the right have been processed with an edge Laplacian $5 \times 5$ filter to highlight the gradients in the image. Times for the image are (top to bottom): $0 \mathrm{~ms}$, $0.657 \mathrm{~ms}, 1.000 \mathrm{~ms}, 2.029 \mathrm{~ms}$, and $4.000 \mathrm{~ms}$, respectively. The arrows indicate the locations of the blast wave

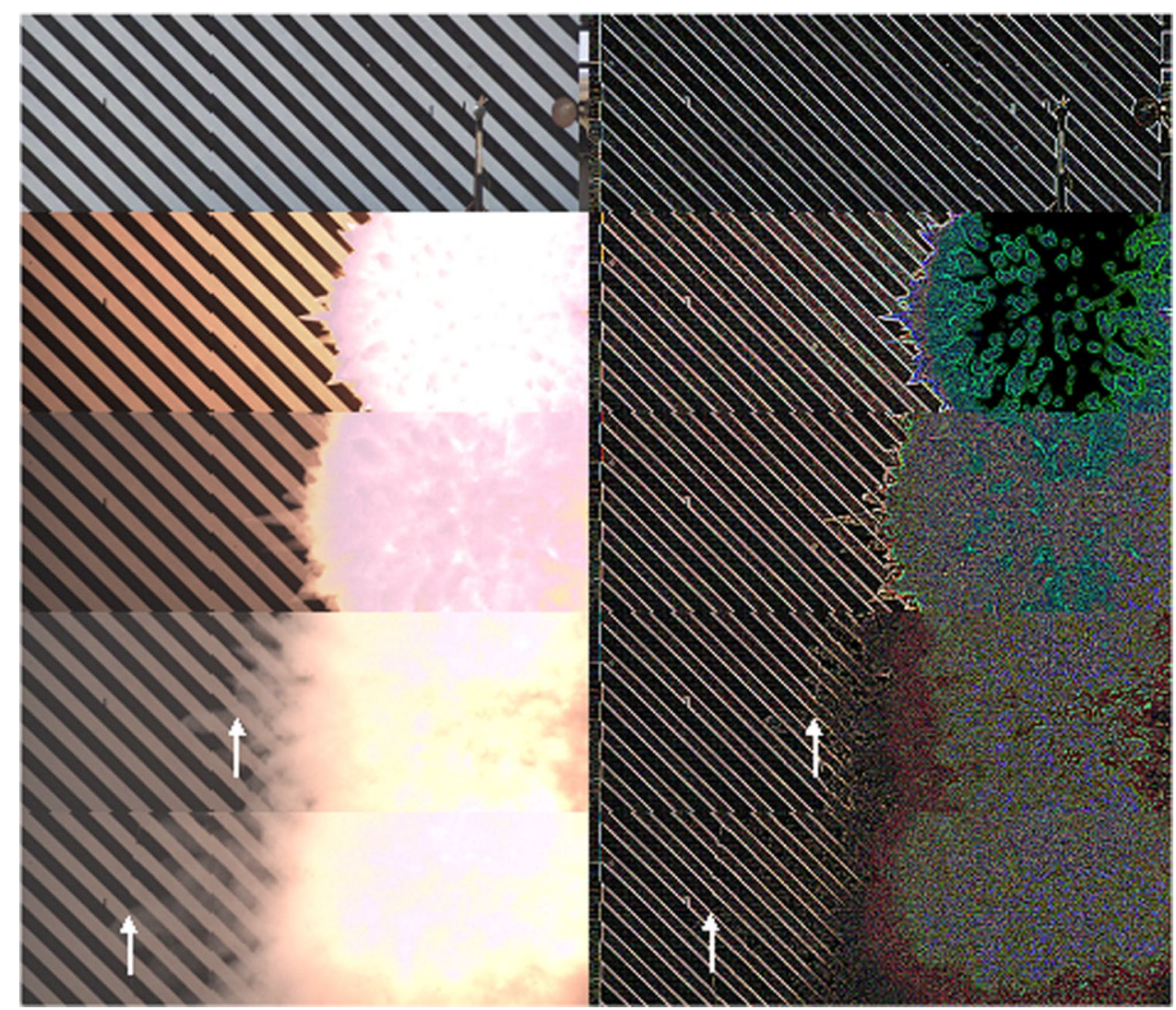


the pixel intensity value according to pixel color. For each trial, the intensity of the first image is subtracted from all the images, so the $\mathscr{L}$ value is equal to 0 before detonation of the charge. The detonation time corresponds to the start of the sharp rise of the luminosity that saturates the camera. The integrated intensity decreases sharply after the detonation but increases again during the afterburning phase which occurs after the primary blast wave reflects off the ground, after about $2 \mathrm{~ms}$. The value of $\mathscr{L}$ captured at a mass fraction of $30 \% \mathrm{H}-50 \mathrm{Al}$ is significantly larger than that of the baseline. Conversely, adding the same mass fraction of glass particles reduces the luminosity considerably. Values of $\mathscr{L}$ can be even negative due to the soot formed that causes the video image to be darker than the initial image before the detonation. Note also the absence of an afterburning phase for the inert particles. The analysis of the spatially integrated luminescence presented here remains purely qualitative due to the numerous camera settings that influence the pixel intensity, such as the lens aperture, exposure time, and extreme dynamic range (EDR) setting, which is a feature of the operation of Phantom cameras that reduces the specific intensity of pixels that are approaching saturation.

\subsection{Fireball expansion and blast propagation (pressure gauges and videography)}

The relative position of the maximum extent of the luminous fireball and the shock wave for the three previous trials is shown in Fig. 11. Note that the maximum extent of the fireball is approximate and cannot be considered a precisely defined measurement since in cases where some of

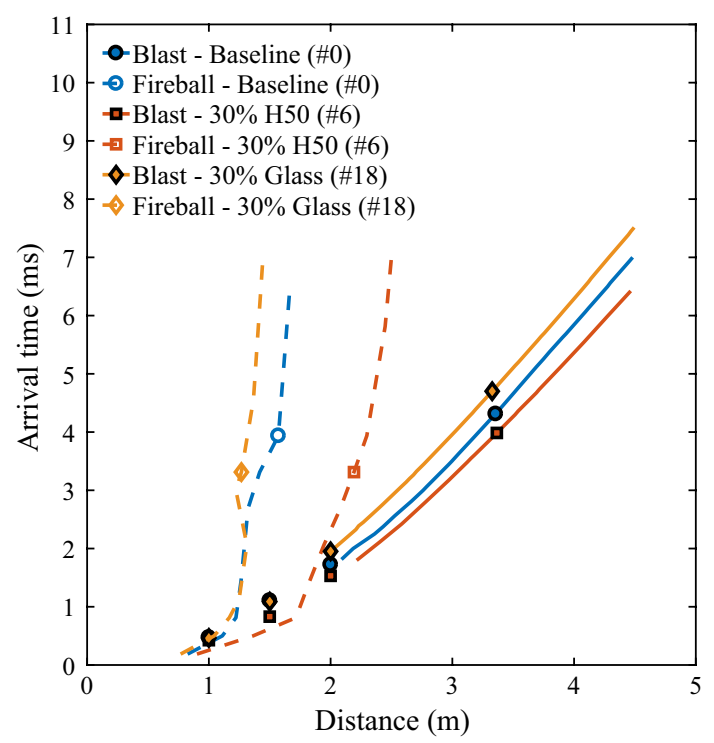

Fig. 11 Blast front and fireball trajectories plotted for the baseline explosive (trial \#0) and with mixtures with $30 \mathrm{wt} \% \mathrm{H}-50$ (trial \#6) and $30 \mathrm{wt} \%$ glass beads (trial \#18) the pixels on the camera sensor are saturated, some charge leakage (or pixel bleed) between adjacent pixels can occur. The blast arrival times captured with the pressure gauges are also reported. In general, the blast time of arrival does not match perfectly with the blast time of arrival obtained with the videography analysis in the mid field. The discrepancy is explained by the fact that the pressure gauge at $2.0 \mathrm{~m}$ from the charge is not located within the field of view of camera 1 (see Fig. 1) and implies that the blast propagation is not isotropic. Nevertheless, the blast times of arrival obtained from videography measurements are offset to match the arrival time at the pressure gauge in the mid field (Fig. 11). As mentioned before, for the reactive case $(30 \% \mathrm{H}-50)$, the first two pressure gauges are engulfed in the fireball and the last gauge located typically very close to the fireball surface.

Analyzing the blast times of arrival is of interest to highlight the contribution of the particle reaction to the blast wave propagation. The energy deposited into the gas by the reaction of the particles may couple with the blast front and increase its velocity. Conversely, the absorption of the explosive energy by inert particles may reduce the energy available to support the blast, hence decreasing the blast velocity. Figure 11 indicates that the blast times of arrival are smaller for the trial with aluminum particles compared to the baseline from $0.426 \mathrm{~ms}$ (at $1.0 \mathrm{~m}$ ) and more significantly from $0.830 \mathrm{~ms}$ (at $1.5 \mathrm{~m}$ ). This suggests that the aluminum reaction contributes to increasing the blast velocity. Conversely, the blast time of arrival is higher when glass particles are added to the explosive mixture, indicating that the addition of inert particles contributes to decreasing the blast velocity. A contraction of the fireball size after a few milliseconds due to rarefaction waves is visible for the inert case (30\% glass) and for the baseline case, but not observed for the trial with aluminum. The comparison between the trajectories of the fireballs indicates that the fireballs generated by the aluminized explosives grow to a larger size than the fireballs generated with the baseline explosive. Conversely, the size of the fireball generated by the explosive diluted with inert particles tends to be smaller than that of the baseline explosive.

\subsection{Blast time of arrival in the near-to-mid field (pressure gauges)}

Figure 12a summarizes the times of arrival, for a given type of powder, at a distance of $2.0 \mathrm{~m}$ from the charge. Values of times of arrival for the different trials are normalized by the time of arrival for the baseline charge (i.e., $t_{\mathrm{a}} / t_{\mathrm{a} \text {-baseline }}$ ). The performance of the baseline is equal to 1 and is represented by the dashed blue line. When the explosive is diluted with glass particles, the blast times of arrival are systematically delayed compared to the baseline. The arrival times increase 


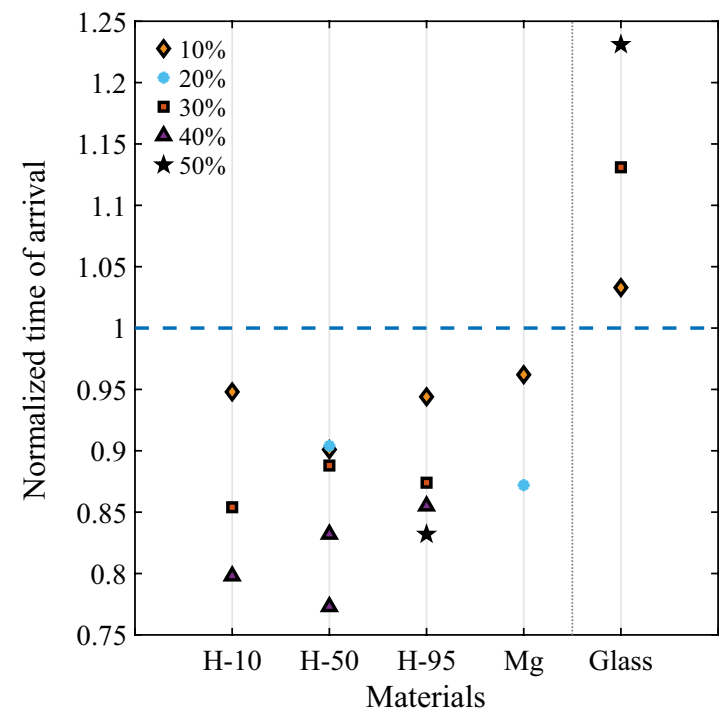

(a)

Fig. 12 a Effect of the mass fraction on the normalized blast times of arrival $\left(t_{\mathrm{a}} / t_{\mathrm{a} \text {-baseline }}\right)$ calculated from pressure gauge data at $2.0 \mathrm{~m}$ from the charge and sorted by type of powders. The baseline value

monotonically with the mass fraction by up to $23 \%$ of the baseline value at a mass fraction of $50 \%$. Conversely, the addition of reactive ( $\mathrm{Al}$ or $\mathrm{Mg}$ ) particles in the gelled NM systematically reduces the blast times of arrival, for all trials tested, compared to the baseline case. The reduction in the arrival times is generally a monotonic function of the mass fraction. The addition of $20 \mathrm{wt} \%$ of magnesium particles reduces the blast time of arrival by $13 \%$ compared to the pure gelled NM. The addition of 40-50 wt $\%$ of aluminum particles typically reduces the blast time of arrival by $17-23 \%$ compared to the baseline explosive depending on the powder considered. Figure 12a also indicates that the particle size of the aluminum particles has very little influence on the blast arrival times. Note the variation of the normalized arrival times between the repeated trials $(\mathrm{H}-50$ particles at a mass fraction of $40 \%$ ). This discrepancy suggests that the small variations of the normalized arrival times, when comparing the different aluminum particle sizes, are on the order of the stochastic variation of the experiments. The blast times of arrival for each trial, recorded by the pressure gauges, are presented in Tables 3 and 4 in the Appendix.

\subsection{Peak blast overpressures in the mid field (pressure gauge)}

Similar to Fig. 12a, the normalized peak blast overpressure values at the same distance are reported in Fig. 12b. The graph shows that the peak blast overpressures are systematically augmented for all charges tested with reactive materials and mitigated for all the charges tested with inert glass

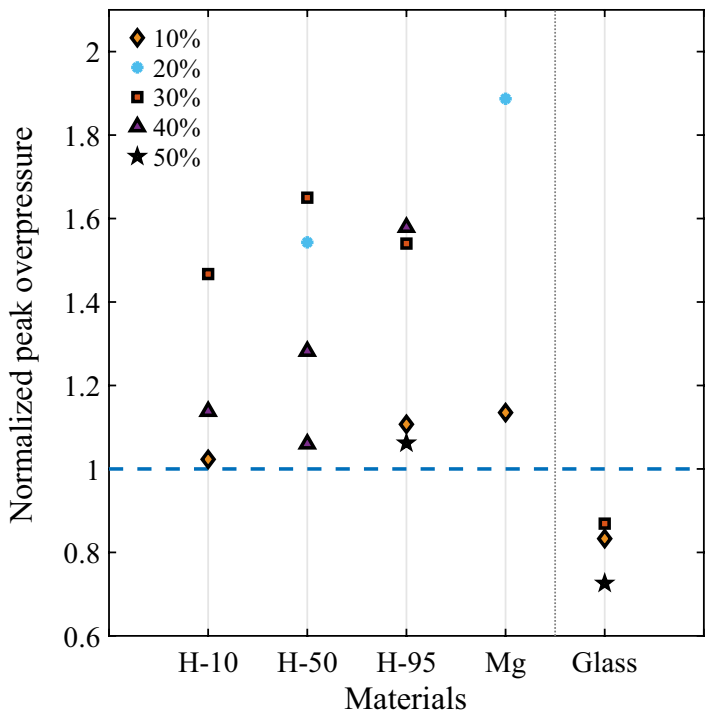

(b)

(gelled NM without particles) is represented by the horizontal dashed blue line. b Same plot but for the normalized peak blast overpressure $\left(\Delta P_{\mathrm{s}} / \Delta P_{\text {s-baseline }}\right)$

particles, compared to the baseline. Anomalously, the charge with $20 \mathrm{wt} \%$ magnesium particles outperforms all the other charges at enhancing the peak blast overpressures with an augmentation of $89 \%$ compared to the baseline, although data were not obtained for higher Mg mass loadings due to problems with the pressure sensors. For charges with aluminum particles, the highest performance was obtained at mass loadings of $30 \mathrm{wt} \%$ (H-10, H-50) or $40 \mathrm{wt} \%$ (H-95), with an augmentation of $47-65 \%$ compared to the baseline value. This suggests that the peak blast overpressure enhancement does not change monotonically with the mass fraction, contrary to the blast arrival times. This lack of correlation between the arrival times and peak overpressure may be due to the error associated with the extraction method mentioned in Sect. 3. Conversely, the addition of $50 \mathrm{wt} \%$ of glass particles in the gelled NM mitigates the peak overpressure by around $27 \%$. As observed for the blast arrival times, the normalized peak blast overpressures show little dependence on the aluminum particle size excepted for a mass fraction of $40 \%$. At this mass fraction, the normalized peak blast overpressures with H-95 particles outperform those obtained with $\mathrm{H}-10$ particles by $44 \%$. Nevertheless, this discrepancy is cautionary due to the stochastic variation between repeated trials (see the results for $\mathrm{H}-50$ particles). All the peak overpressure values are presented in Tables 5 and 6 in the Appendix. 


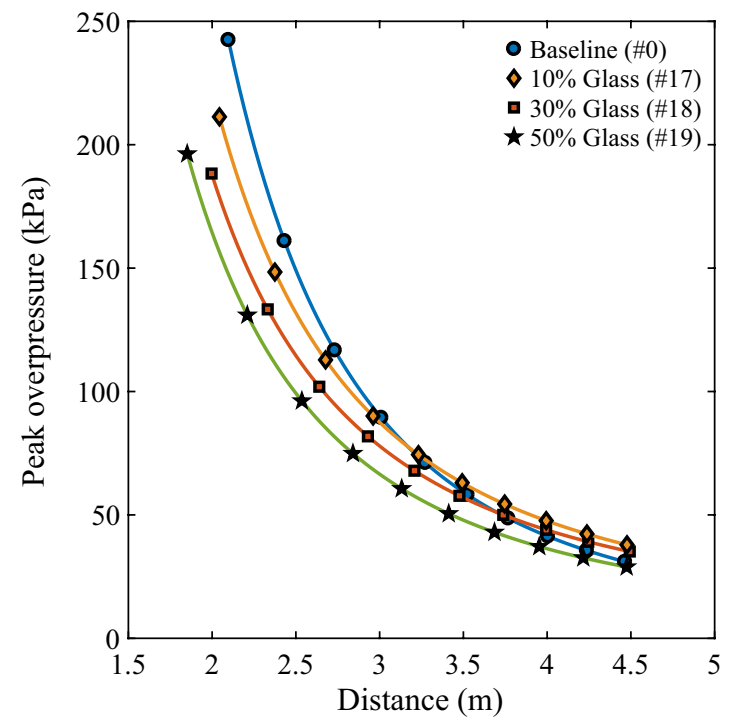

(a)

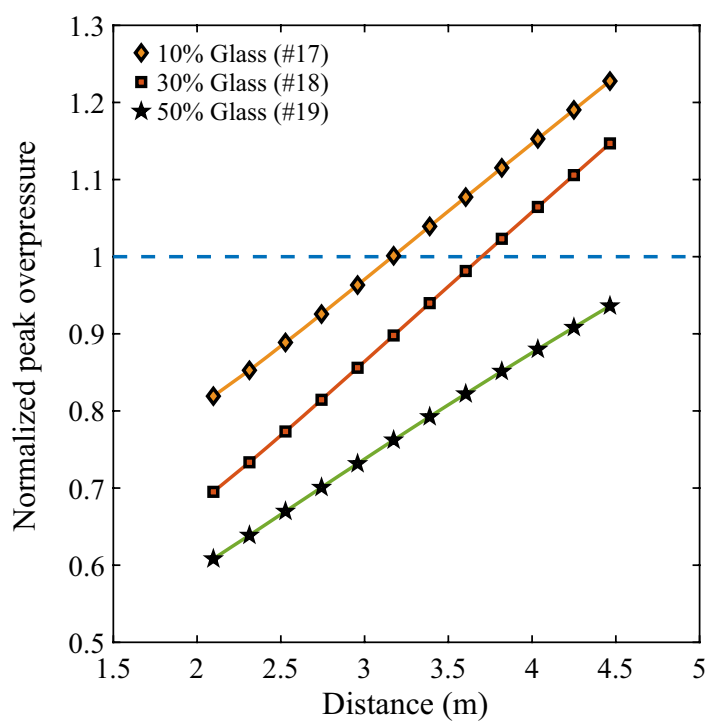

(b)

Fig. 13 a Effect of particle mass fraction on peak blast wave overpressure decays for glass particles. The baseline charge (\#0) contains only gelled NM with no particles. b Peak overpressure efficiencies relative to the baseline explosive (dashed blue line)

\subsection{Effect of particle material and mass loading on blast decay in the mid-to-far field (videography)}

Figure 13a shows the decay of the peak blast overpressure with distance, in the mid-to-far field, for trials with glass particles, with various mass fractions of the additive powder. Note that the relative errors resulting mainly from the tracking of the blast front on the videos are typically of the order of the size of the data markers and are consequently not shown. To highlight the performance, the normalized peak overpressures are also shown in Fig. 13b. As shown in Fig. 12, the performance of the baseline trial is equal to 1 and is represented by a blue dashed line. The peak blast overpressure decays for all the other materials are reported in the Appendix in Figs. 19 and 20.

Adding the glass particles reduces the strength of the blast wave in the mid field, with the reduction in pressure increasing as more glass powder is added (by up to $37.5 \%$ at around $2 \mathrm{~m}$ ). In the far field, the peak blast overpressure recovers almost to the same value as the base explosive charge for $50 \mathrm{wt} \%$ addition of glass and even exceeds the baseline case for $10 \mathrm{wt} \%$ and $30 \mathrm{wt} \%$ addition, by up to $22.8 \%$ even though the charges with added glass have a reduced amount of explosive. This behavior is consistent with the earlier results from Pontalier et al. [10-13], who attributed the near-field reduction in blast pressure to the energy transfer from the detonation products to the kinetic energy and heating of the inert particles, and the later time blast pressure recovery to the pressure perturbations induced by the particle-flow interactions.

With the addition of reactive particles, Fig. 14 shows that in all cases, the particle reaction enhances the strength of the blast wave over the baseline explosive, with the enhancement greatest in the far field. In the mid field, i.e., just outside the maximum fireball radius, the particle reaction counteracts the pressure reduction observed for inert particle addition, such that the peak blast overpressure is higher than that of the baseline case by between 5\% (10 wt $\% \mathrm{H}-95)$ and 27\% (40 wt $\% \mathrm{H}-10$ ) at around $2.2 \mathrm{~m}$. Further from the charge, the combination of the particle reaction and the motion of the particles within the products sustains the peak blast overpressure at a higher level than for the homogeneous liquid explosive, so that the peak blast enhancement with the addition of reactive particles can attain a value of up to almost twice the baseline value (for $20 \mathrm{wt} \% \mathrm{Mg}$ ), at $4.5 \mathrm{~m}$.

The effect of the mass fraction of added particles, for a given type of particle, on the blast overpressure decay is shown in Figs. 13 and 14. For the addition of glass particles, the attenuation of the blast wave overpressure increases monotonically with the mass fraction, as expected. Conversely, with added H-10 aluminum particles, the blast enhancement increases monotonically with the mass fraction. In the case of $\mathrm{H}-50$ and $\mathrm{H}-95$ particles, the blast enhancement depends on the location from the charge and is not necessarily a monotonic function of the mass fraction. In the far field, the maximum peak overpressure is attained at a mass fraction of $30-40 \%$ for $\mathrm{H}-50$ and $50 \%$ for H-95. However, this assertion is subject to the scatter observed 


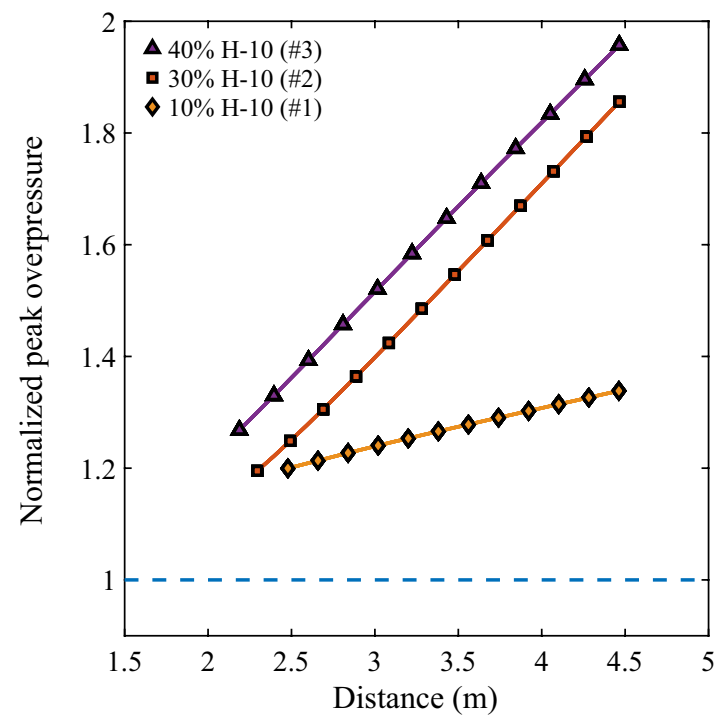

(a) $\mathrm{H}-10$

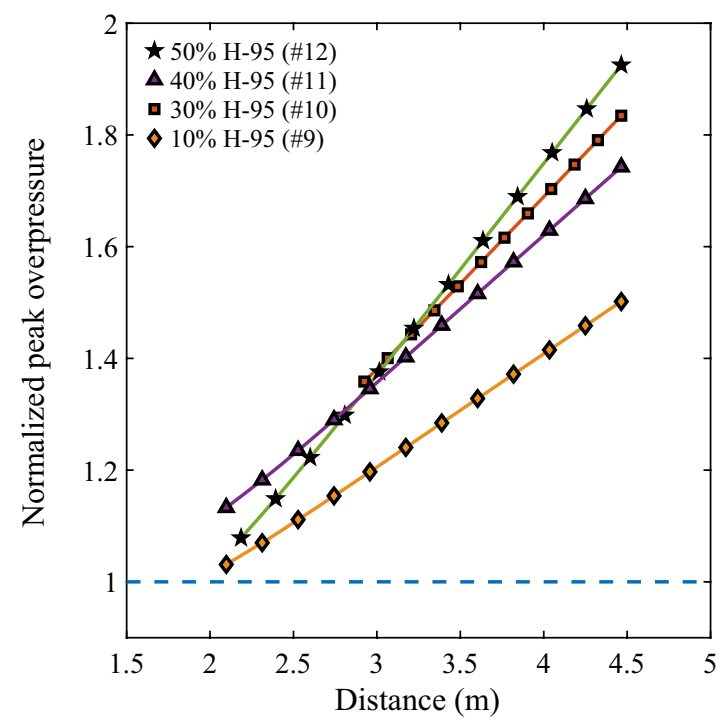

(c) $\mathrm{H}-95$

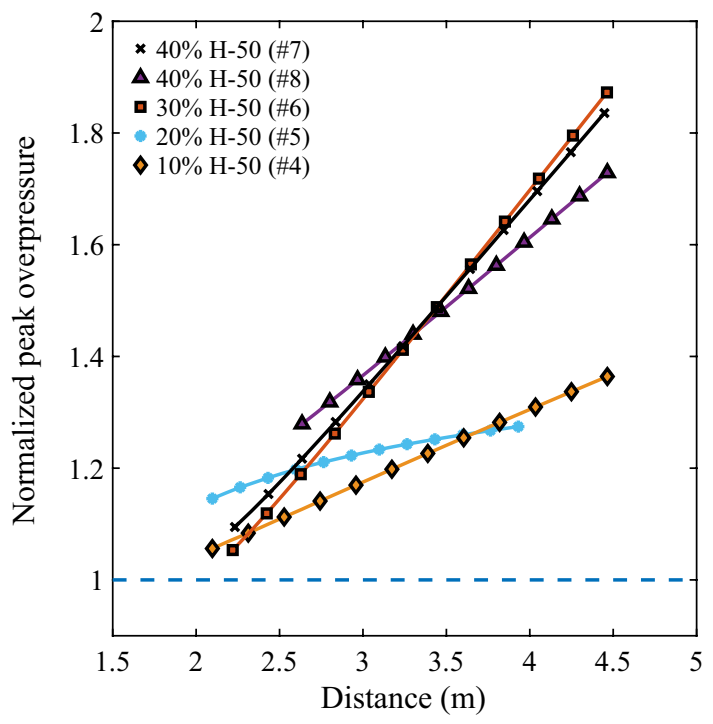

(b) $\mathrm{H}-50$

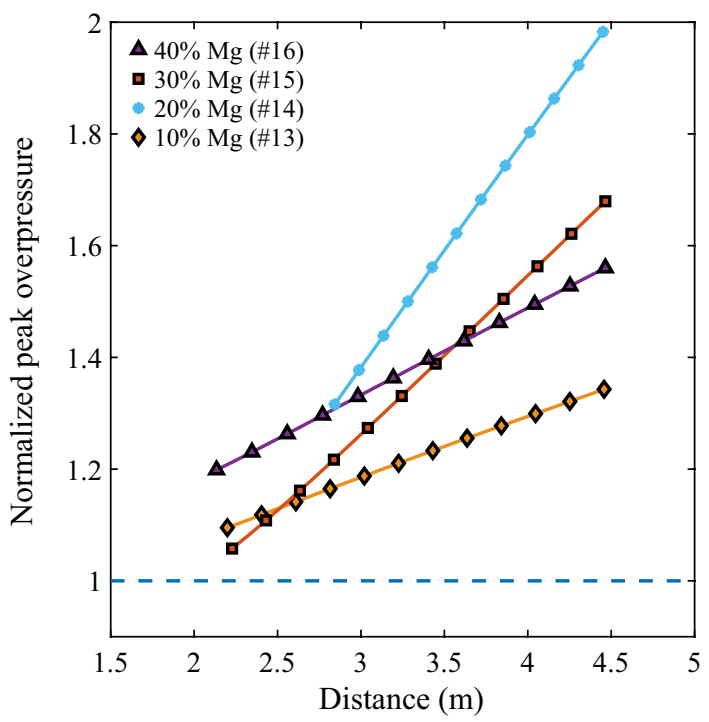

(d) $\mathrm{Mg}$

Fig. 14 Effect of the mass fraction on the peak overpressure efficiencies relative to the baseline explosive (dashed blue line) plotted for a $\mathrm{H}-10$ Al, b H-50 Al, c H-95 Al, and d GRAN 17 Mg

between the two repeated trials $(40 \% \mathrm{H}-50$, trials \#7 and \#8). The results for $\mathrm{Mg}$ indicate that the blast enhancement is greatest for a particle mass fraction of $20 \%$, at least in the far field. Note that for aluminum particles, the blast enhancement increases more rapidly when the mass fraction is high (30-50\%) compared to low mass fractions (10-20\%).

For aluminum particles, at a specific mass fraction of $30 \%$, Fig. 15 shows that the peak blast overpressure exhibits no systematic dependence on particle size. The effects of particle size on blast overpressure at other mass fractions are shown in Fig. 20 in the Appendix. The results for aluminum particles again do not show a systematic variation with particle size. In the mid field, the smallest aluminum particles yield slightly higher normalized peak overpressures for all mass fractions, whereas in the far field, the larger particles generate larger normalized overpressures at a mass fraction of $10 \%$ (after $3.5 \mathrm{~m}$ ). However, at a mass fraction of $40 \%, \mathrm{H}-10 \mathrm{Al}$ particles yield the highest peak overpressure values in the far field. Figure 20 also shows that with the addition of magnesium particles the normalized peak overpressures in the mid field are comparable to those for aluminum particles, but are lower than the aluminum values in the far field for mass fractions of $10 \mathrm{wt} \%, 30 \mathrm{wt} \%$, and $40 \mathrm{wt} \%$, which is consistent with the 


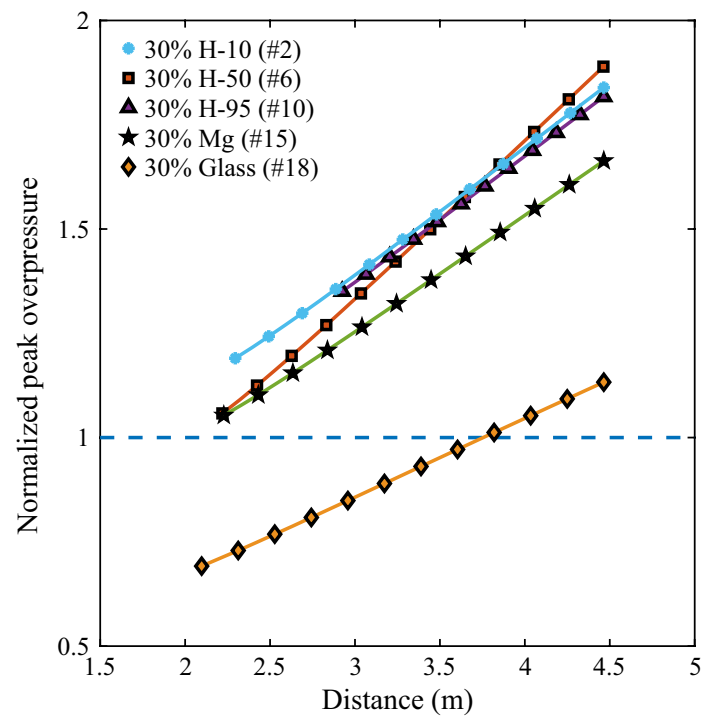

Fig. 15 Effect of material and particle size on the peak overpressure efficiencies relative to the baseline explosive (dashed blue line), for a particle mass fraction of $30 \%$

smaller specific energy release from magnesium relative to aluminum. The comparison between the peak overpressure values at 2.0 meters from the charge, obtained with the pressure gauge or the videography analysis, is shown in the Appendix, in Table 7. The peak blast overpressure discrepancies between the two methods are not systematic. This observation suggests that the strength of the blast wave is not uniform in every direction.

\section{Discussion}

The results presented in this study show strong evidence of prompt reaction of the aluminum or magnesium particles embedded in the gelled NM mixture. The reactions are sufficiently exothermic to counteract the heat and momentum transfer from the detonation products to the particles and contribute to enhancing the luminosity (see Fig. 10) and size (see Fig. 11) of the fireball, as well as the velocity and overpressure of the blast wave (see Fig. 12). Conversely, adding inert glass particles serves to absorb some of the explosive energy, which reduces the luminosity and size of the fireball as well as the velocity and overpressure of the blast wave, at least in the mid field. Farther from the charge, some of the kinetic energy of the particles is transferred back to the surrounding gas which leads to a recovery of the blast wave overpressure, in some cases to values above that of the baseline explosive alone (see Fig. 13). This blast recovery phenomenon, attributed to the pressure disturbances created by the particle-flow interactions, was described in a previous
Table 2 Blast times of arrival for all trials at $1.0 \mathrm{~m}$ from the charge indicating the early contribution of the energy release of $\mathrm{Al} / \mathrm{Mg}$ particles to the blast wave

\begin{tabular}{ccccc}
\hline Trial & Material & wt $\%$ & $t_{\mathrm{a}}(\mathrm{ms}-1.0 \mathrm{~m})$ & $\boldsymbol{t}_{\mathrm{a}} / \boldsymbol{t}_{\mathrm{a}-\text { baseline }}$ \\
\hline$\# 0$ & Baseline & - & 0.474 & $\mathbf{1 . 0 0 0}$ \\
\hline$\# 1$ & H-10 Al & 10 & 0.376 & $\mathbf{0 . 7 9 3}<\mathbf{1}$ \\
$\# 2$ & H-10 Al & 30 & 0.379 & $\mathbf{0 . 8 0 0}<\mathbf{1}$ \\
$\# 3$ & H-10 Al & 40 & 0.464 & $\mathbf{0 . 9 7 8}<\mathbf{1}$ \\
\hline$\# 4$ & H-50 Al & 10 & 0.353 & $\mathbf{0 . 7 4 5}<\mathbf{1}$ \\
$\# 5$ & H-50 Al & 20 & 0.455 & $\mathbf{0 . 9 6 0}<\mathbf{1}$ \\
$\# 6$ & H-50 Al & 30 & 0.426 & $\mathbf{0 . 8 9 9}<\mathbf{1}$ \\
$\# 7$ & H-50 Al & 40 & 0.436 & $\mathbf{0 . 9 1 9}<\mathbf{1}$ \\
$\# 8$ & H-50 Al & 40 & 0.398 & $\mathbf{0 . 8 4 0}<\mathbf{1}$ \\
\hline$\# 9$ & H-95 Al & 10 & 0.510 & $\mathbf{1 . 0 7 5} \approx \mathbf{1}$ \\
$\# 10$ & H-95 Al & 30 & 0.424 & $\mathbf{0 . 8 9 3}<\mathbf{1}$ \\
$\# 11$ & H-95 Al & 40 & 0.461 & $\mathbf{0 . 9 7 2}<\mathbf{1}$ \\
$\# 12$ & H-95 Al & 50 & 0.458 & $\mathbf{0 . 9 6 5}<\mathbf{1}$ \\
\hline$\# 13$ & Gran 17 Mg & 10 & 0.447 & $\mathbf{0 . 9 4 3}<\mathbf{1}$ \\
$\# 14$ & Gran 17 Mg & 20 & 0.387 & $\mathbf{0 . 8 1 6}<\mathbf{1}$ \\
$\# 15$ & Gran 17 Mg & 30 & 0.431 & $\mathbf{0 . 9 0 8}<\mathbf{1}$ \\
$\# 16$ & Gran 17 Mg & 40 & 0.452 & $\mathbf{0 . 9 5 3}<\mathbf{1}$ \\
\hline$\# 17$ & Glass beads & 10 & 0.488 & $\mathbf{1 . 0 2 8}$ \\
$\# 18$ & Glass beads & 30 & 0.465 & $\mathbf{0 . 9 8 0}$ \\
$\# 19$ & Glass beads & 50 & 0.617 & $\mathbf{1 . 3 0 1}$ \\
\hline & & & &
\end{tabular}

work with explosive charges containing a variety of different embedded particles [10]. The contribution of these disturbances may also depend on the particle size. Small particles tend to adapt more quickly to the flow in comparison with larger particles and hence transfer their energy to the flow more rapidly [11].

The influence of the energy release from the particles on the blast wave propagation depends on the location of the energy release. If the energy release occurs immediately behind the blast wave, the local increase in gas pressure will promptly enhance the blast overpressure. Even if the particle energy release occurs some distance behind the blast wave, the pressure disturbances generated can catch up to the blast wave in the mid or far field since the local sound speed behind the blast wave is increased due to the shock heating as well as the particle reaction. In general, with the addition of reactive particles, the blast wave peak overpressure increases linearly with distance from the charge, when normalized relative to the baseline explosive, due to the effect noted above (see Fig. 14). Effectively, the particle reaction continues to contribute to augmenting the blast wave overpressure in the far field due to the continual arrival of pressure disturbances at the blast wave front.

In the near field within the fireball, the blast wave is not directly visible, but the motion of the blast wave can be tracked using signals from the pressure gauges that are engulfed by the fireball. For example, the times for the arrival of the blast wave at the first gauge, located $1.0 \mathrm{~m}$ from 
the charge, are reported in Table 2 and are less than that for the baseline explosive, which is consistent with the higher blast wave speed noted above. From Fig. 11, it is evident that the combustion products fireball extends beyond this pressure gauge for the baseline explosive charge and eventually grows to a radius of about $1.5 \mathrm{~m}$. Hence, it is expected that when aluminum particles are added to the explosive, by the time that the blast wave reaches this first pressure gauge, the aluminum particles will have been exposed primarily to the oxidizers within the detonation products, which predominantly consist of water for charges with NM. The minimum observed arrival time is $353 \mu \mathrm{s}$, and hence the particles must have started to react before this time. Since the nearest pressure transducer is located $1 \mathrm{~m}$ from the charge, with the current diagnostics used, it is not possible to resolve the rate of energy release from the particles at earlier times than this.

It is of interest to consider the nature of this early-time reaction of aluminum with the water in the detonation products. This reaction produces molecular hydrogen gas which will contribute to inflating the size of the fireball. This hot hydrogen gas is highly reactive, and it will react promptly when it mixes with the oxygen in the surrounding atmosphere at the contact surface between the detonation products and air. The rate of reaction of the hydrogen will be limited by the mixing rate with the surrounding atmosphere which in turn is influenced by the rate of growth of the perturbations that develop at the contact surface due to the Rayleigh-Taylor instability as the interface decelerates.

In Fig. 11, the growth of the radius of the fireball with added aluminum particles begins to separate from that of the baseline explosive as early as $200 \mu \mathrm{s}$. This may be due to the production of hydrogen and subsequent reaction with the surrounding air. After this time, the fireball continues to expand over several milliseconds. The reactions within the fireball, due to the particles as well as from residual soot from the baseline oxygen-deficient explosive, are also enhanced by the mixing induced by the passage of the secondary and the ground-reflected blast waves after about 2 $\mathrm{ms}$, which leads to an increase in fireball luminosity (see Fig. 10).

The oxygen balance of an explosive provides a measure of the availability of oxidizers for reacting with aluminum in the explosive decomposition products. Alternatively, equilibrium calculations can be carried out to estimate the amount of aluminum that could theoretically react within the detonation reaction zone as well as during adiabatic expansion of the products. Calculations were carried out using the equilibrium code CHEETAH 2.0 [39] to determine the maximum amount of aluminum that could potentially completely react with the products of the detonation of the gelled $\mathrm{NM}$ at the CJ detonation state as well as if the products were allowed to adiabatically expand to $1 \mathrm{~atm}$. The result of these calculations with the BKWC library indicated that a maximum of $26 \mathrm{wt} \%$ of $\mathrm{Al}$ mixed with the gelled NM could potentially completely react by the end of the detonation zone assuming that equilibrium conditions are attained. Furthermore, if the products are allowed to expand adiabatically to atmospheric pressure, additional reaction of $\mathrm{Al}$ is possible and in this case an initial mixture containing $36 \mathrm{wt} \%$ would result in complete reaction of the $\mathrm{Al}$ after expansion. If more species are allowed in the detonation products (JCZS library), the percentages go up to $39 \%$ and $63 \%$, respectively. These values provide an upper bound for the amount of aluminum that could react with the detonation products without additional mixing with oxygen in the surrounding air. Due to the finite rates of aluminum oxidation and mixing, the actual amount of $\mathrm{Al}$ that could react in the products will be less.

An important observation from the present experimental results is that the blast enhancement with added aluminum particles does not systematically depend on particle size. Despite varying the particle size by one order of magnitude (or the surface area by two orders of magnitudes), the normalized blast overpressure was not significantly different for the various particle sizes, and in the far field the results did not vary systematically with particle size at the various mass loadings considered. In a previous work, Peuker et al. [15] found negligible particle size effects for 3-40- $\mu \mathrm{m}$ aluminum particles on blast enhancement from small-scale aluminized explosive charges. These results suggest that conventional scaling laws for aluminum particle combustion based on surface area correlations that are derived from single-particle experimental results at quiescent atmospheric conditions must be modified to describe the particle reaction within the extreme conditions within the detonation products at early times.

In the detonation reaction zone for condensed explosives, pressures are on the order of tens of gigapascals [14], with temperatures ranging from 3000 to $5000 \mathrm{~K}$ [40] and slip velocities above $1 \mathrm{~km} / \mathrm{s}$ [41]. Under these extreme conditions, the particle reaction mechanism and transport properties are completely unknown. Within the detonation products, the density of the flow is initially of the same order as the density of the metallic particles such that extremely high heat transfer rates may be possible. In supercritical conditions, aluminum oxide dissolves in water [42], and hence the preexisting oxide coating on aluminum particles provides no barrier against the dissolution of the particle and subsequent anaerobic reaction with the detonation products. Note that the reaction of the aluminum with the oxidizers in the detonation products (primarily $\mathrm{H}_{2} \mathrm{O}$ ) is not coincident with the energy release from the reactions. The formation of some aluminum sub-oxides (e.g., $\mathrm{AlO}, \mathrm{Al}_{2} \mathrm{O}$ ) is weakly exothermic, but the primary energy release is associated with the chemical condensation of the stable aluminum oxide $\mathrm{Al}_{2} \mathrm{O}_{3}$, 
which occurs only after a degree of expansion of the products has taken place.

In contrast with the lack of systematic dependence of blast performance on the particle size, the ratio of particle mass to the explosive mass does influence the blast enhancement. As the particle mass loading is increased for a fixed volume, the explosive is diluted. Initially, the energy release from the added particles overcomes this dilution effect, as the maximum energy release for complete oxidation of the particles is several times that of the energy release of the explosive itself (31.5 kJ/g for $\mathrm{Al}$ [4], $24.7 \mathrm{~kJ} / \mathrm{g}$ for $\mathrm{Mg}$ [43] vs $6.4 \mathrm{~kJ} / \mathrm{g}$ for NM [44]). Eventually, with a sufficiently high solid mass fraction, the heat and momentum losses to the particles will weaken the blast strength. This suggests that there exists an optimal particle loading for maximum blast strength, which will depend on both the particle and explosive properties. In the present experiments, the normalized peak overpressure is maximized for mass fractions between 30 and $50 \%$ for aluminum particles (see Fig. 14). The smallest mass loading (10\%) consistently gave the smallest blast overpressures, and the overpressure augmentation increases with distance from the charge, possible due to the energy release from hydrogen gas as it mixes and rapidly burns with the surrounding air.

\subsection{Energy-based blast overpressure scaling}

To compare the blast wave overpressure decay with distance for explosive charges of different sizes, it is conventional to scale the distance with the mass of explosive (Hopkinson scaling $[45,46])$, or the explosive energy release, which depends on the explosive mass. For a multi-component explosive, it appears to be more meaningful to scale the distance with a parameter that depends on the total energy release, or the sum of the energy released by each component, which in general will be different, rather than the total mass of the charge [4]. Using Bach and Lee's convention [47], we define a scaled distance $R_{0}$ (or explosive characteristic length), defined by the following expression:

$R_{0}=\left(\frac{E_{\text {total }}}{\rho_{0} c_{0}^{2} k_{j}}\right)^{\frac{1}{j+1}}$

where $\rho_{0}$ and $c_{0}^{2}$ are, respectively, the density and the speed of sound of the blast propagating medium (atmospheric air in this case); $j$ and $k_{j}$ are geometrical factor set, respectively, at 2 and $4 \pi$ for a $3 \mathrm{D}$ spherical blast wave. If it is assumed that the ambient air is an ideal gas, the previous equation can be rewritten as follows:
$R_{0}=\left(\frac{E_{\text {total }}}{4 \pi \gamma P_{0}}\right)^{\frac{1}{3}}$

where $\gamma$ is the ratio of specific heats, taken to be 1.405 for air (in the mid-to-far field) and $P_{0}$ is the value of the atmospheric pressure, which changes from trial to trial. To account for the multiple sources of energy release, $E_{\text {total }}$ is defined as follows:

$E_{\mathrm{total}}=m_{\mathrm{NM}} \times q_{\mathrm{NM}}+m_{\mathrm{C} 4} \times q_{\mathrm{C} 4}+\varepsilon \times m_{\mathrm{me}} \times q_{\mathrm{me}}$.

Here, $m(\mathrm{~g})$ is the mass of each component. For $m_{\mathrm{NM}}$, the mass of explosive is calculated without the $4.4 \mathrm{wt} \%$ inert additives (GMB + PMMA). Note that in the previous definition, the total energy $E_{\text {total }}$ is assumed to be released instantaneously after the detonation. The quantity $q$ is the energy release per unit mass of each component $(\mathrm{kJ} / \mathrm{g})$, and the last term refers to the energy release from the metal combustion, with the subscript "me" (or metal) corresponding to either $\mathrm{Al}$ or $\mathrm{Mg}$, depending on the trial. The parameter $\varepsilon$, which may vary between 0 and 1 , corresponds to the fraction of the energy released from the metal combustion that is assumed to contribute to supporting the blast wave propagation. Note that this $\varepsilon$ value does not represent the amount of $\mathrm{Al}$ or $\mathrm{Mg}$ that reacts. Indeed, even if the timescale of particle energy release is short, it is not instantaneous, as assumed in (4). This finite timescale for the energy release implies that the percentage of metal reacting is generally higher than the $\varepsilon$ value. In the limit of long times for the energy release of the metal particles, $\varepsilon$ will tend to zero, whereas for instantaneous and complete energy release $\varepsilon$ will approach unity. Note that since the charges in the present investigation have a constant volume, the relative contribution of the base explosive and the particle reaction to the blast overpressure will change as the particle material or mass loading is changed. Values of energy release for complete combustion of the various components, i.e., $q_{\mathrm{NM}}, q_{\mathrm{C} 4}, q_{\mathrm{Al}}$, and $q_{\mathrm{Mg}}$, are set, respectively, to $6.4 \mathrm{~kJ} / \mathrm{g}$ [44], $6.7 \mathrm{~kJ} / \mathrm{g}$ [48], $31.5 \mathrm{~kJ} / \mathrm{g}$ [4], and $24.7 \mathrm{~kJ} / \mathrm{g}$ [43]. Note that the values of heats of combustion for magnesium and aluminum particles are those for complete reactions with molecular oxygen. However, these values are equivalent to the total heat of combustion assuming that the particles first react primarily with water in the detonation products to form molecular hydrogen gas, followed by the combustion of the hydrogen with the oxygen present in air, i.e.,

$q_{\mathrm{Al}}(31.5 \mathrm{~kJ} / \mathrm{g})\left\{\begin{array}{l}2 \mathrm{Al}(\mathrm{s})+3 \mathrm{H}_{2} \mathrm{O}(\mathrm{g}) \rightarrow \mathrm{Al}_{2} \mathrm{O}_{3}(\mathrm{~s})+3 \mathrm{H}_{2}(\mathrm{~g}) \\ 3 \mathrm{H}_{2}(\mathrm{~g})+1.5 \mathrm{O}_{2}(\mathrm{~g}) \rightarrow 3 \mathrm{H}_{2} \mathrm{O}(\mathrm{g})\end{array}\right.$

and 
$q_{\mathrm{Mg}}(24.7 \mathrm{~kJ} / \mathrm{g})\left\{\begin{array}{l}\mathrm{Mg}(\mathrm{s})+\mathrm{H}_{2} \mathrm{O}(\mathrm{g}) \rightarrow \mathrm{MgO}(\mathrm{s})+\mathrm{H}_{2}(\mathrm{~g}) \\ \mathrm{H}_{2}(\mathrm{~g})+0.5 \mathrm{O}_{2}(\mathrm{~g}) \rightarrow \mathrm{H}_{2} \mathrm{O}(\mathrm{g})\end{array}\right.$.

If the two reactions given in each case above are added together, as expected the resulting reaction gives the direct oxidation of the metal with molecular oxygen to form the metal oxide. In the case of aluminum, complete oxidation of aluminum to $\mathrm{Al}_{2} \mathrm{O}_{3}$ releases an energy of $31.5 \mathrm{~kJ} / \mathrm{g}$. The two intermediate reactions given above release roughly equal amounts of energy. In particular, the first reaction of aluminum with water releases $15.1 \mathrm{~kJ} / \mathrm{g}$, with the remainder of the energy released by the reaction of hydrogen gas. It should be reemphasized that the parameter $\varepsilon$ introduced above corresponds to the fraction of the energy release that is assumed to contribute to the blast wave propagation, and cannot be directly related to the fraction of aluminum that reacts. For example, a value of $\varepsilon$ of 0.5 could correspond roughly to either half of the aluminum present fully reacting, or all of the aluminum present reacting only with water to form hydrogen.

Water vapor is not the only oxidizer present in the detonation products of NM [49] but is the most prevalent. According to CHEETAH 2.0 (BKWC library), the detonation product gases of NM at the CJ detonation state are composed, by order of prevalence, of water $\left(\mathrm{H}_{2} \mathrm{O}\right)$, carbon monoxide $(\mathrm{CO})$, nitrogen $\left(\mathrm{N}_{2}\right)$, hydrogen $\left(\mathrm{H}_{2}\right)$, and carbon dioxide $\left(\mathrm{CO}_{2}\right)$. The quantity of water vapor exceeds the quantity of carbon monoxide by more than one order of magnitude.
The $\mathrm{Al} / \mathrm{Mg}$ particles could alternatively react with all the other oxidizers than water. In particular, previous publications have shown the possibility of metallic particles to react, at microsecond timescales, in hydrogen-free explosives, through other reaction pathways including reaction with $\mathrm{CO}_{2}$ as an oxidizer [25]. This implies that early-time metal reaction can contribute to the blast strength through different reaction pathways and that for different explosive compositions. Nevertheless, the reaction timescales and pathways may influence the overall blast wave dynamics as well as the peak blast overpressure values. The $q$ values presented in (6) and (7) are the most energetic ones and do not change if the primary oxidizer is substituted. For instance, the $\mathrm{Al}$ reaction with $\mathrm{CO}_{2}$ and the subsequent combustion of the produced $\mathrm{CO}$ with the $\mathrm{O}_{2}$ of the air give the same value of energy release $\left(q_{\mathrm{Al}}=31.5 \mathrm{~kJ} / \mathrm{g}\right)$.

If the peak blast overpressure results for charges containing inert glass particles are plotted versus scaled distance, the results are shown in Fig. 16. Figure 16a shows the overpressure decay in dimensional coordinates (same as the plot in Fig. 13a). In Fig. 16b, the results are shown versus non-dimensional distance $R / R_{0}$ [with $\varepsilon=0$ in the definition of $E_{\text {total }}$ in (5)]. As expected, the curves collapse reasonably well, with small discrepancies with the baseline results apparent in the mid and far field, suggesting that scaling with the energy released by the explosive (both NM and C4) for a liquid explosive mixture diluted by inert particles is reasonable. In the scaled coordinates, the small reduction in overpressure with the addition of particles in the near field

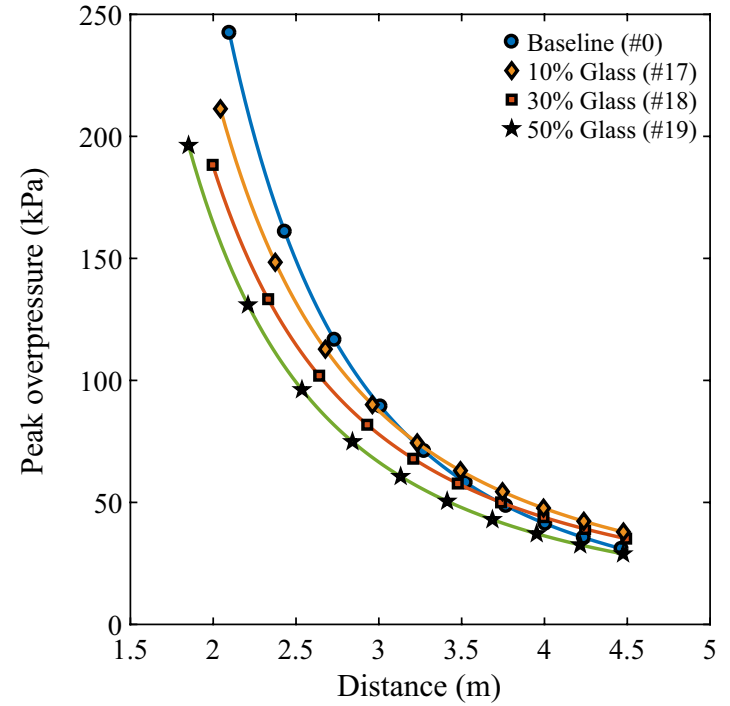

(a)

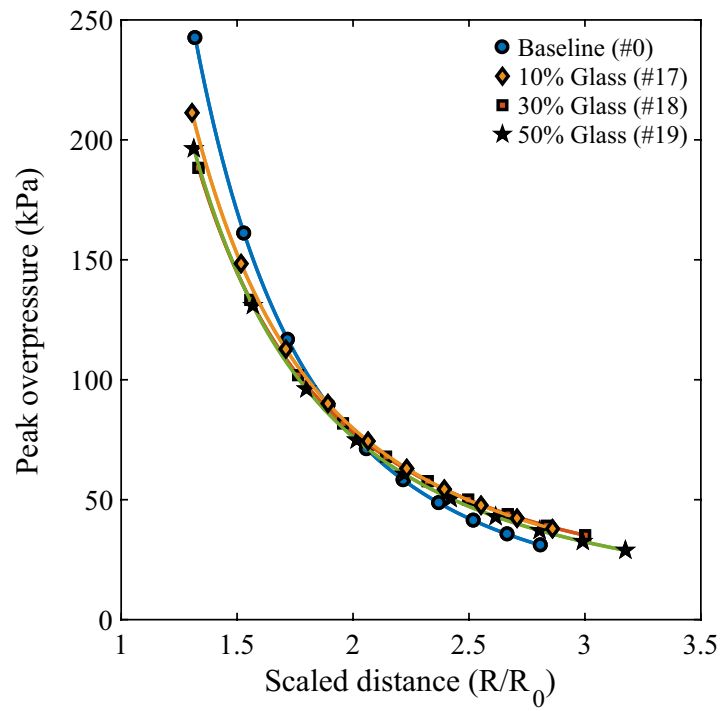

(b)

Fig. 16 Peak blast overpressure decays with distance for glass particles with $\mathbf{a}$ dimensional radius, and $\mathbf{b}$ with scaled distance, $R / R_{0}$, where $R_{0}$ accounts for the explosive energy only [NM+C4, $\varepsilon=0$ in (5)] 


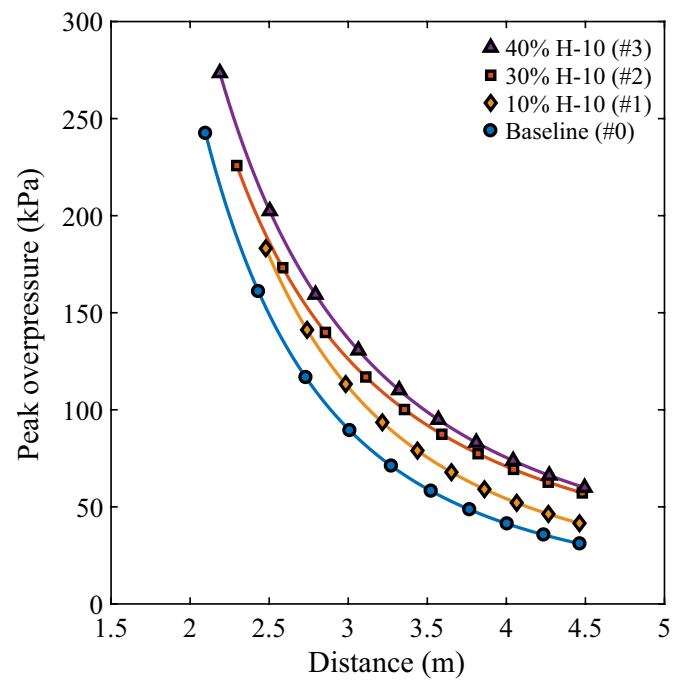

(a) $\mathrm{H}-10$

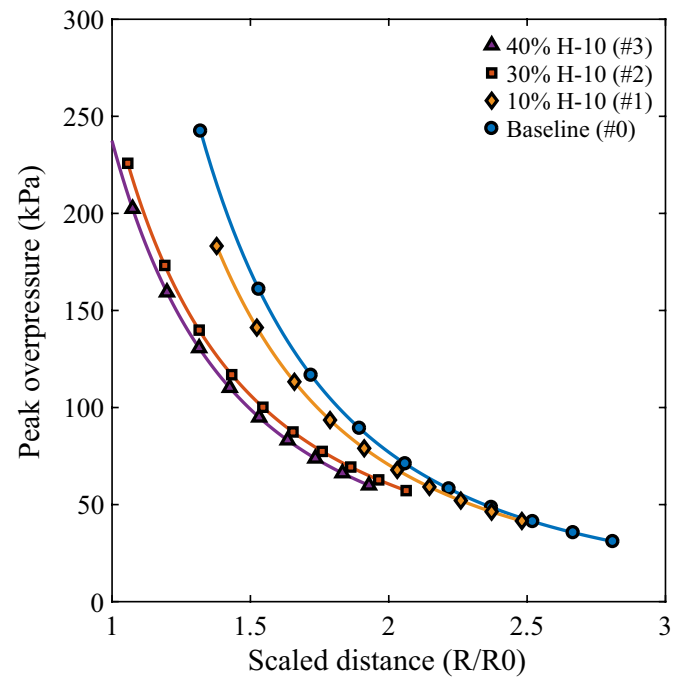

(c) $\mathrm{H}-10, \varepsilon=1$

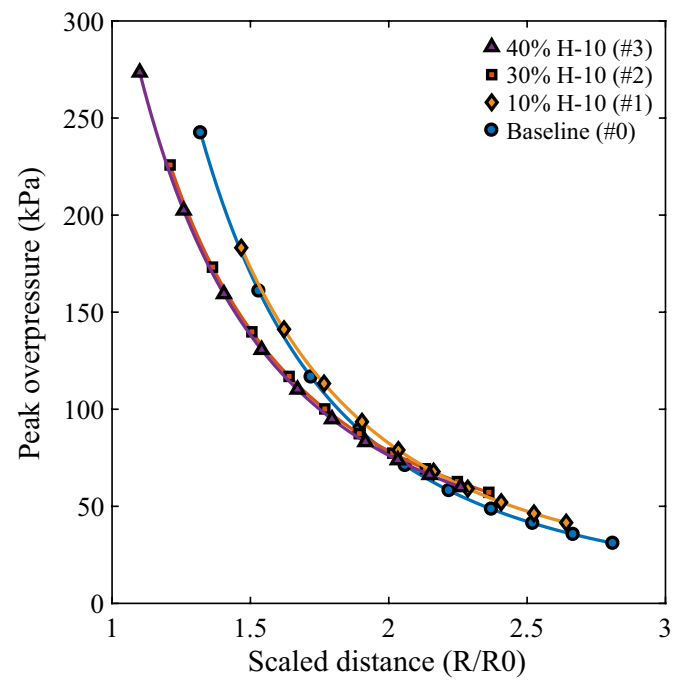

(e) $\mathrm{H}-10, \varepsilon=0.5$

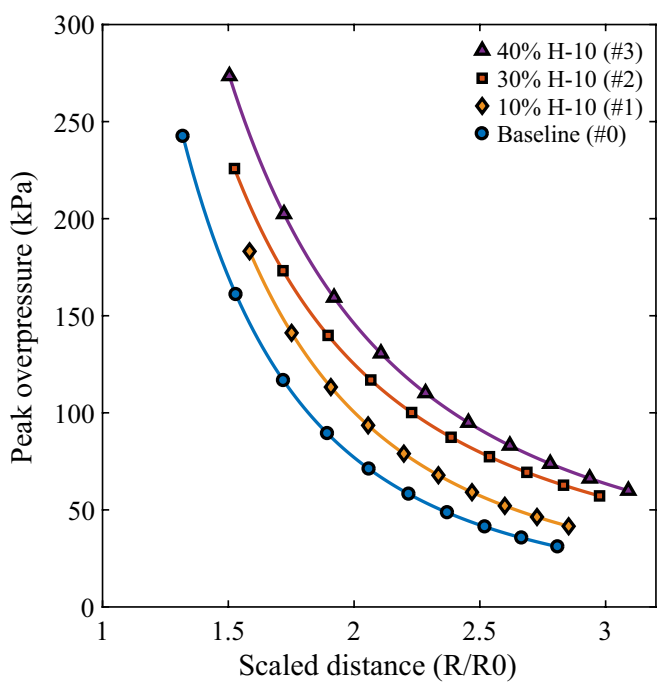

(b) $\mathrm{H}-10, \varepsilon=0$

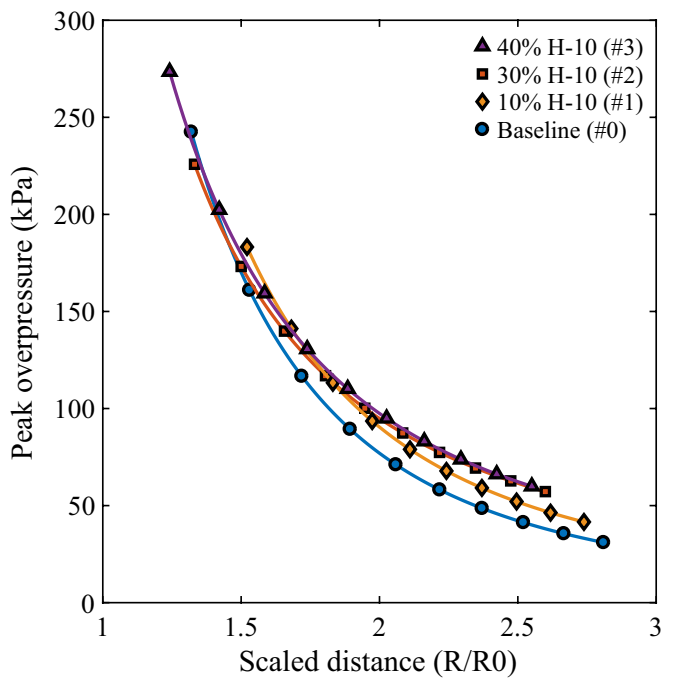

(d) $\mathrm{H}-10, \varepsilon=0.25$ 
4Fig. 17 Peak blast overpressure decays with distance for H-10 aluminum particles with a dimensional radius, and $\mathbf{b}$ with scaled distance, $R / R_{0}$, where $R_{0}$ accounts for the explosive energy only [NM $+\mathrm{C} 4, \varepsilon=0$ in (5)]. c Peak blast overpressure decays with distance for $\mathrm{H}-10$ aluminum particles assuming a full contribution of the $\mathrm{Al}$ chemical energy $(\varepsilon=1)$. d Peak blast overpressure decays with distance for $\mathrm{H}-10$ aluminum particles assuming that $25 \%(\varepsilon=0.25)$ of the Al chemical energy contributes to the blast front. e Peak blast overpressure decays with distance for $\mathrm{H}-10$ aluminum particles assuming that $50 \%(\varepsilon=0.5)$ of the $\mathrm{Al}$ chemical energy contributes to the blast front

is accounted for by the energy lost to heating and accelerating the particles, whereas the small overpressure excess in the far field, as noted earlier, is due to particle-gas interactions $[10,11]$. This figure shows that the reduction in the blast performance for explosives with added inert particles is primarily due to the dilution effect.

In Fig. 17a, the blast overpressure decay for the addition of $\mathrm{H}-10 \mathrm{Al}$ particles is shown with respect to dimensional distance. In the remainder of the plots, the results are shown plotted versus non-dimensional distance, in which different values of $\varepsilon$ were assumed in the definition of scaled distance, to determine if the overpressure results collapse. The working assumption is that if the overpressure results collapse in the scaled coordinates, at a given distance, then the value of $\varepsilon$ chosen represents the effective contribution of the total energy release by the particle reaction to the blast front. In Fig. 17b, c, the scaled distance is chosen assuming, respectively, no aluminum energy release $(\varepsilon=0)$ and that the full aluminum energy release contributes to the blast propagation $(\varepsilon=1)$. In both cases, the curves generally fail to collapse, indicating that these assumptions are not consistent with the experimental results. The sole exception to that is the assumption of complete energy release for a solid mass fraction of $10 \%$, which results in the overpressure curve nearly overlapping the baseline explosive case in the far field (Fig. 17c). This suggests, at this small mass fraction, that the energy release associated with complete oxidation of the aluminum powder contributes to the peak blast overpressure by the time the blast reaches the far field. The complete reaction of the particles in the detonation products is theoretically possible at this mass fraction, as demonstrated earlier with CHEETAH calculations. Figure $17 \mathrm{~d}$ shows the blast overpressure results plotted with a scaling assuming that $25 \%$ of the particle energy release contributes to the blast (i.e., $\varepsilon=0.25$ ). The results collapse in the near field, at a distance near the edge of the fireball interface. At this distance, the particles will have reacted primarily with the detonation products, so one interpretation of the results is that one-half of aluminum particles fully react with water within the products and the energy release associated with this reaction contributes to the nearfield blast overpressure. In Fig. 17e, the results are plotted assuming that $50 \%$ of the particle energy release contributes to the blast strength. The results collapse in the far field, suggesting that additional energy is released, possibly due to reaction of the hydrogen produced, that contributes to strengthening the blast wave as it moves from the near field to the far-field region.

A similar methodology is used to plot the results for H-50 and $\mathrm{H}-95$ aluminum and for magnesium particles in Fig. 18, with values chosen for $\varepsilon$ ranging from 0.15 to 0.5 for the aluminum particles and 0.3 to 0.65 for the magnesium particles. In the far field, for aluminum particles, with $\varepsilon=0.5$, the curves for mass loadings of $40-50 \%$ approach that of the baseline explosive, suggesting that the fraction of the particle energy release that has contributed to the blast wave overpressure by the far-field approaches $50 \%$. For smaller particle mass loadings $(10-30 \%)$, the scaled overpressure values actually exceed the baseline values, suggesting that at these mass loadings even more than half the particle energy release contributes to the blast wave. Note again that the energy that contributes to the blast does not reflect the real mass of reactive particles that react. 


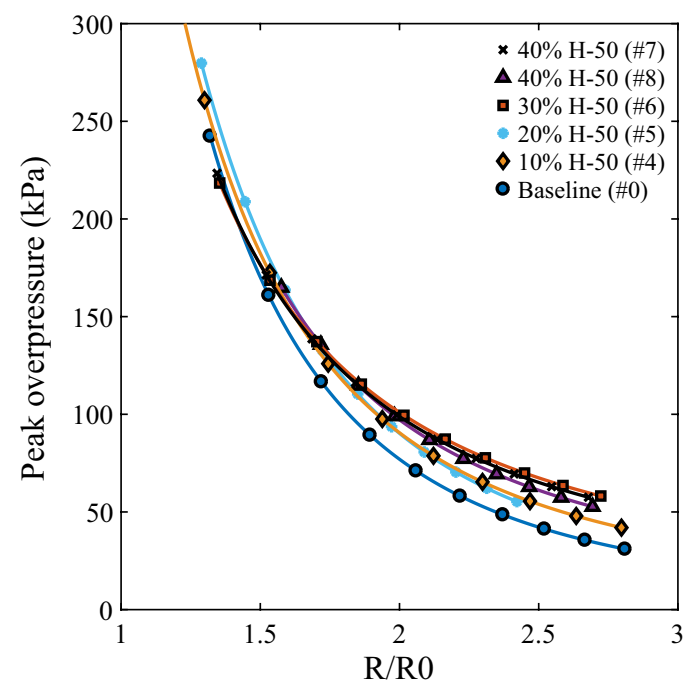

(a) $\mathrm{H} 50, \varepsilon=0.15$

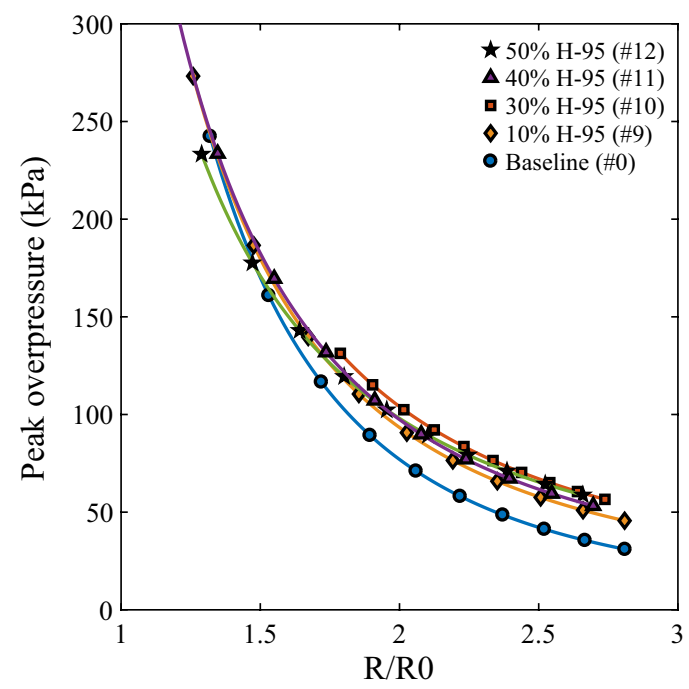

(c) $\mathrm{H}-95, \varepsilon=0.15$

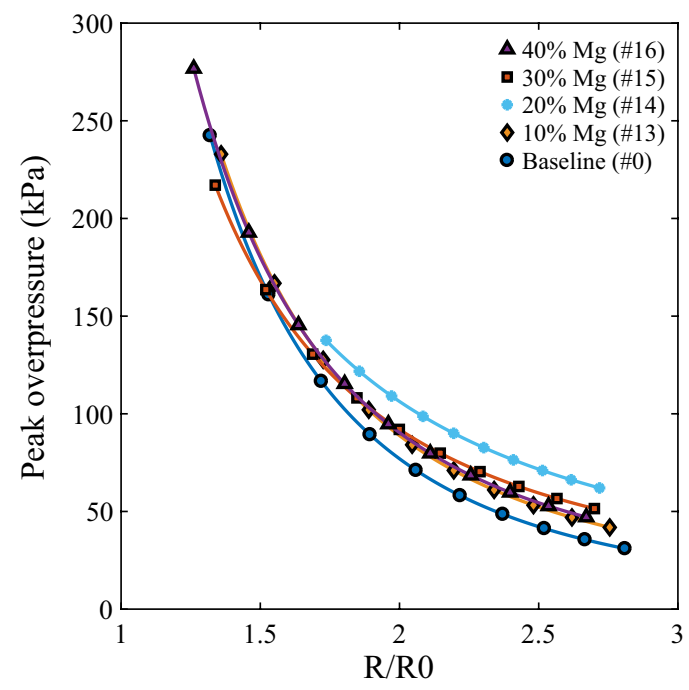

(e) $\mathrm{Mg}, \varepsilon=0.3$

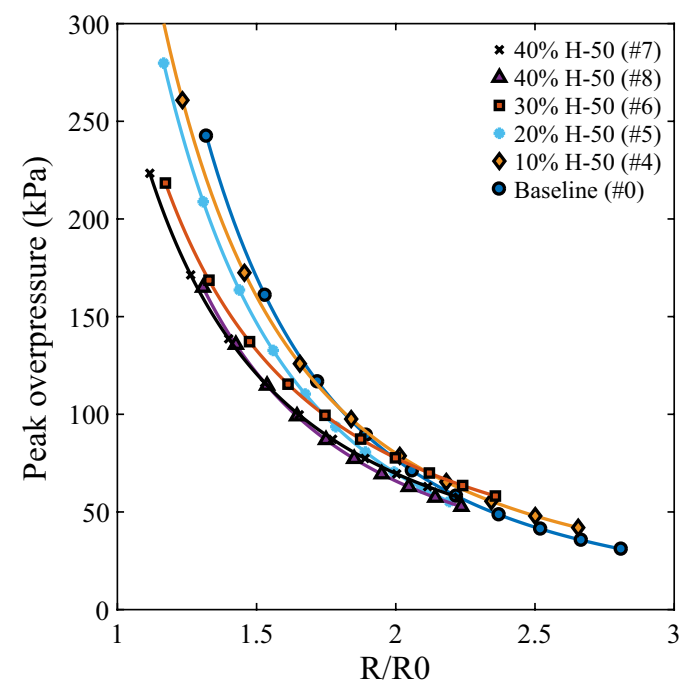

(b) $\mathrm{H}-50, \varepsilon=0.5$

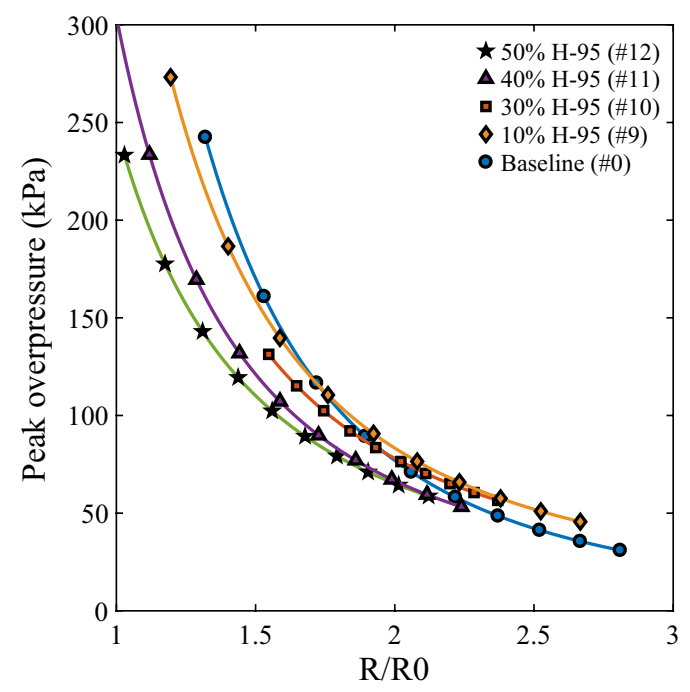

(d) $\mathrm{H}-95, \varepsilon=0.5$

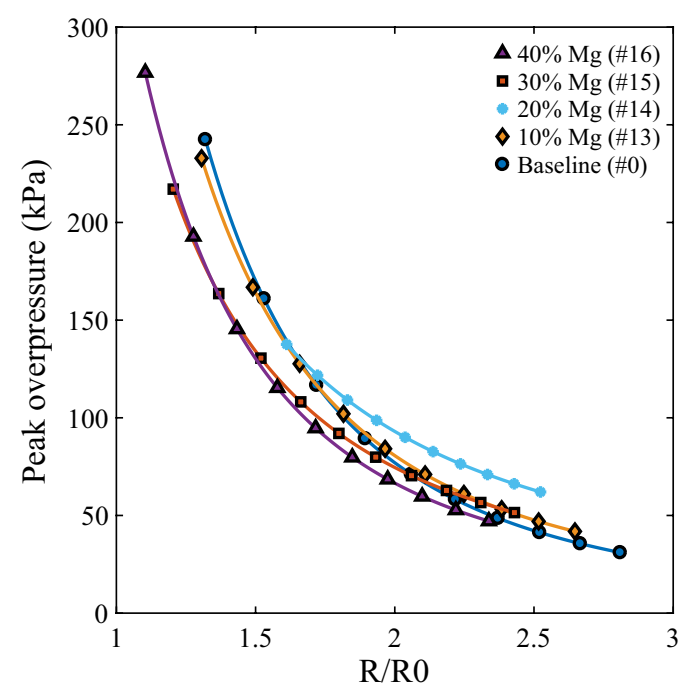

(f) $\mathrm{Mg}, \varepsilon=0.65$ 
4Fig. 18 Same graphs as in Fig. 17 considering that a assuming that $15 \%(\varepsilon=0.15)$ of the $\mathrm{H}-50 \mathrm{Al}$ chemical energy contributes to the blast front, b assuming that $50 \%(\varepsilon=0.5)$ of the $\mathrm{H}-50 \mathrm{Al}$ chemical energy contributes to the blast front, $\mathbf{c}$ assuming that $15 \%(\varepsilon=0.15)$ of the $\mathrm{H}-95 \mathrm{Al}$ chemical energy contributes to the blast front, d assuming that $50 \%(\varepsilon=0.5)$ of the $\mathrm{H}-95 \mathrm{Al}$ chemical energy contributes to the blast front, e assuming that $30 \%(\varepsilon=0.3)$ of the $\mathrm{Mg}$ chemical energy contributes to the blast front, $\mathbf{f}$ assuming that $65 \%$ $(\varepsilon=0.65)$ of the $\mathrm{Mg}$ chemical energy contributes to the blast front

\section{Conclusions}

The effect of adding both inert (glass) and reactive (aluminum and magnesium) particles to gelled nitromethane on the performance of the blast wave generated by the detonation of the resulting heterogeneous explosive in constant volume charges was determined experimentally. The results were compared with the baseline case of the homogeneous explosive itself. Blast arrival times and peak blast overpressures in the near-to-mid field were analyzed from pressure gauge data. High-speed videography was used to infer the peak overpressure decays in the mid-to-far field. The main conclusions of this study are:

1. The addition of inert glass particles mitigates the peak blast overpressure by up to $38 \%$ in the mid field (i.e., just outside the maximum extent of the fireball), with the mitigation increasing with particle mass loading. When the peak blast overpressure is plotted as a function of non-dimensional distance accounting for the total energy release of the explosive, the blast decay results largely collapse, suggesting that the blast performance depends mainly on the explosive energy available. The addition of particles slightly attenuates the blast in the near field (due to heat and momentum transfer to the particles) and augments the blast in the far field (due to particle-flow interactions), consistent with previous results $[10,11]$.

2. Based on the reduced arrival time of the blast wave at the nearest pressure gauge with $\mathrm{Al}$ or $\mathrm{Mg}$ particles, relative to that of the baseline explosive, the energy release from the particles influences the blast wave propagation within about $300 \mu$ s of charge detonation in all cases. The peak blast overpressure was found to be increased by up to almost twice the baseline value in the far field. The best blast performance with aluminum particles was observed at a particle mass loading between $30 \%$ and $50 \%$ depending on the distance from the charge.

3. Although the Al particle size was varied over an order of magnitude, the blast enhancement effect was rela- tively insensitive to particle size. This suggests that the use of correlations for particle reaction time that depend monotonically on particle size is not sufficient to predict the blast performance. New particle reaction models are needed that are also consistent with the early metal reactions observed in metal acceleration experiments with metalized explosives.

4. By plotting the blast overpressure results versus an energy-scaled distance, and comparing the resulting overpressure decay with the baseline explosive, it is possible to gain insight into the degree to which the particle reaction contributes to the blast wave overpressure when the blast wave reaches various distances. The results for the metalized explosives containing aluminum or magnesium particles suggest that at a particle mass fraction of $10 \%$, most of the energy release from the particle reaction has contributed to the blast propagation by the far field, which here is defined as distances greater than $3 \mathrm{~m}$ from $1 \mathrm{~L}$ volume charges. At particle mass fractions of 30-50\%, more than half of the particle reaction energy contributes to the blast wave overpressure by the far field. The most probably reaction pathway for the aluminum in nitromethane consists of early submillisecond reaction of the aluminum with the water in the detonation products, releasing hydrogen, followed by combustion of the hydrogen with the surrounding air in the highly turbulent mixing zone near the fireball interface. Nevertheless, it is hypothesized that the possibility of the contribution to the blast of the early-time metal energy release would also occur in hydrogen-free compounds through other reaction pathways.

The present results demonstrate that sub-millisecond energy release from the reaction of the metal particles with the water in the detonation products contributes to augmenting the blast strength. Additional experimental diagnostics very near the charge are needed to further resolve the rate of particle energy release at early times. Some insight into the partition of the particle energy release history between the detonics (microseconds), early expansion (hundreds of microseconds), and later fireball expansion (millisecond) stages of the phenomena may be obtained by comparing hydrocode predictions of the blast decay with experimental results, assuming a parametric variation in the particle energy release rate, and efforts in this direction are currently underway [50]. 
Table 3 Blast times of arrival for all trials at $1.0 \mathrm{~m}, 1.5 \mathrm{~m}$, and $2.0 \mathrm{~m}$ from the charge, captured with pressure transducers

\begin{tabular}{ccccccccc}
\hline Trial & Material & wt $\%$ & $t_{\mathrm{a}}(\mathrm{ms}-1.0 \mathrm{~m})$ & $\boldsymbol{t}_{\mathrm{a}} / \boldsymbol{t}_{\mathrm{a}-\text { baseline }}$ & $t_{\mathrm{a}}(\mathrm{ms}-1.5 \mathrm{~m})$ & $\boldsymbol{t}_{\mathrm{a}} / \boldsymbol{t}_{\mathrm{a}-\text { baseline }}$ & $t_{\mathrm{a}}(\mathrm{ms}-2.0 \mathrm{~m})$ & $\boldsymbol{t}_{\mathrm{a}} / \boldsymbol{t}_{\mathrm{a}-\text { baseline }}$ \\
\hline$\# 0$ & Baseline & - & 0.474 & $\mathbf{1 . 0 0 0}$ & 1.107 & $\mathbf{1 . 0 0 0}$ & 1.725 & $\mathbf{1 . 0 0 0}$ \\
\hline$\# 1$ & $\mathrm{H}-10 \mathrm{Al}$ & 10 & 0.376 & $\mathbf{0 . 7 9 3}$ & 1.099 & $\mathbf{0 . 9 9 3}$ & 1.635 & $\mathbf{0 . 9 4 8}$ \\
$\# 2$ & $\mathrm{H}-10 \mathrm{Al}$ & 30 & 0.379 & $\mathbf{0 . 8 0 0}$ & 0.795 & $\mathbf{0 . 7 1 8}$ & 1.473 & $\mathbf{0 . 8 5 4}$ \\
$\# 3$ & $\mathrm{H}-10 \mathrm{Al}$ & 40 & 0.464 & $\mathbf{0 . 9 7 8}$ & 0.753 & $\mathbf{0 . 6 8 0}$ & 1.377 & $\mathbf{0 . 7 9 8}$ \\
\hline$\# 4$ & H-50 Al & 10 & 0.353 & $\mathbf{0 . 7 4 5}$ & 1.064 & $\mathbf{0 . 9 6 1}$ & 1.554 & $\mathbf{0 . 9 0 1}$ \\
$\# 5$ & H-50 Al & 20 & 0.455 & $\mathbf{0 . 9 6 0}$ & 0.836 & $\mathbf{0 . 7 5 5}$ & 1.559 & $\mathbf{0 . 9 0 4}$ \\
$\# 6$ & H-50 Al & 30 & 0.426 & $\mathbf{0 . 8 9 9}$ & 0.831 & $\mathbf{0 . 7 5 0}$ & 1.531 & $\mathbf{0 . 8 8 8}$ \\
$\# 7$ & H-50 Al & 40 & 0.436 & $\mathbf{0 . 9 1 9}$ & 0.782 & $\mathbf{0 . 7 0 6}$ & 1.436 & $\mathbf{0 . 8 3 2}$ \\
$\# 8$ & H-50 Al & 40 & 0.398 & $\mathbf{0 . 8 4 0}$ & 0.955 & $\mathbf{0 . 8 6 2}$ & 1.333 & $\mathbf{0 . 7 7 3}$ \\
\hline$\# 9$ & H-95 Al & 10 & 0.510 & $\mathbf{1 . 0 7 5}$ & 0.930 & $\mathbf{0 . 8 4 0}$ & 1.629 & $\mathbf{0 . 9 4 4}$ \\
$\# 10$ & H-95 Al & 30 & 0.424 & $\mathbf{0 . 8 9 3}$ & 0.959 & $\mathbf{0 . 8 6 6}$ & 1.507 & $\mathbf{0 . 8 7 4}$ \\
$\# 11$ & H-95 Al & 40 & 0.461 & $\mathbf{0 . 9 7 2}$ & 0.727 & $\mathbf{0 . 6 5 7}$ & 1.475 & $\mathbf{0 . 8 5 5}$ \\
$\# 12$ & H-95 Al & 50 & 0.458 & $\mathbf{0 . 9 6 5}$ & 0.859 & $\mathbf{0 . 7 7 6}$ & 1.436 & $\mathbf{0 . 8 3 2}$ \\
\hline$\# 13$ & Gran 17 Mg & 10 & 0.447 & $\mathbf{0 . 9 4 3}$ & 0.983 & $\mathbf{0 . 8 8 8}$ & 1.660 & $\mathbf{0 . 9 6 2}$ \\
$\# 14$ & Gran 17 Mg & 20 & 0.387 & $\mathbf{0 . 8 1 6}$ & 0.700 & $\mathbf{0 . 6 3 2}$ & 1.504 & $\mathbf{0 . 8 7 2}$ \\
$\# 15$ & Gran 17 Mg & 30 & 0.431 & $\mathbf{0 . 9 0 8}$ & 0.877 & $\mathbf{0 . 7 9 2}$ & N.A. & N.A. \\
$\# 16$ & Gran 17 Mg & 40 & 0.452 & $\mathbf{0 . 9 5 3}$ & 0.887 & $\mathbf{0 . 8 0 1}$ & N.A. & N.A. \\
\hline$\# 17$ & Glass beads & 10 & 0.488 & $\mathbf{1 . 0 2 8}$ & 1.240 & $\mathbf{1 . 1 2 0}$ & 1.782 & $\mathbf{1 . 0 3 3}$ \\
$\# 18$ & Glass beads & 30 & 0.465 & $\mathbf{0 . 9 8 0}$ & 1.088 & $\mathbf{0 . 9 8 3}$ & 1.951 & $\mathbf{1 . 1 3 1}$ \\
$\# 19$ & Glass beads & 50 & 0.617 & $\mathbf{1 . 3 0 1}$ & 1.232 & $\mathbf{1 . 1 1 3}$ & 2.124 & $\mathbf{1 . 2 3 1}$ \\
\hline
\end{tabular}

At every distance, the arrival times are normalized by the baseline value $\left(t_{\mathrm{a}} / t_{\mathrm{a} \text {-baseline }}\right)$ for comparison. Values of arrival times for two specific trials (trials \#15 and \#16), at $2.0 \mathrm{~m}$, are not available due to record problems. At each distance, and for every type of particles, the most efficient trial at reducing (resp. augmenting) the blast arrival is in red (resp. blue)

Table 4 Same as Table 3 but reordered for comparison at a specific mass fraction

\begin{tabular}{ccccccccc}
\hline Trial & Material & wt $\%$ & $t_{\mathrm{a}}(\mathrm{ms}-1.0 \mathrm{~m})$ & $\boldsymbol{t}_{\mathrm{a}} / \boldsymbol{t}_{\mathrm{a}-\text { baseline }}$ & $t_{\mathrm{a}}(\mathrm{ms}-1.5 \mathrm{~m})$ & $\boldsymbol{t}_{\mathrm{a}} / \boldsymbol{t}_{\mathrm{a}-\text { baseline }}$ & $t_{\mathrm{a}}(\mathrm{ms}-2.0 \mathrm{~m})$ & $\boldsymbol{t}_{\mathrm{a}} / \boldsymbol{t}_{\mathrm{a}-\text { baseline }}$ \\
\hline$\# 0$ & Baseline & - & 0.474 & $\mathbf{1 . 0 0 0}$ & 1.107 & $\mathbf{1 . 0 0 0}$ & 1.725 & $\mathbf{1 . 0 0 0}$ \\
\hline$\# 1$ & $\mathrm{H}-10 \mathrm{Al}$ & 10 & 0.376 & $\mathbf{0 . 7 9 3}$ & 1.099 & $\mathbf{0 . 9 9 3}$ & 1.635 & $\mathbf{0 . 9 4 8}$ \\
$\# 4$ & $\mathrm{H}-50 \mathrm{Al}$ & 10 & 0.353 & $\mathbf{0 . 7 4 5}$ & 1.064 & $\mathbf{0 . 9 6 1}$ & 1.554 & $\mathbf{0 . 9 0 1}$ \\
$\# 9$ & $\mathrm{H}-95 \mathrm{Al}$ & 10 & 0.510 & $\mathbf{1 . 0 7 5}$ & 0.930 & $\mathbf{0 . 8 4 0}$ & 1.629 & $\mathbf{0 . 9 4 4}$ \\
$\# 13$ & $\mathrm{Gran} 17 \mathrm{Mg}$ & 10 & 0.447 & $\mathbf{0 . 9 4 3}$ & 0.983 & $\mathbf{0 . 8 8 8}$ & 1.660 & $\mathbf{0 . 9 6 2}$ \\
$\# 17$ & Glass beads & 10 & 0.488 & $\mathbf{1 . 0 2 8}$ & 1.240 & $\mathbf{1 . 1 2 0}$ & 1.782 & $\mathbf{1 . 0 3 3}$ \\
\hline$\# 5$ & $\mathrm{H}-50 \mathrm{Al}$ & 20 & 0.455 & $\mathbf{0 . 9 6 0}$ & 0.836 & $\mathbf{0 . 7 5 5}$ & 1.559 & $\mathbf{0 . 9 0 4}$ \\
$\# 14$ & Gran 17 Mg & 20 & 0.387 & $\mathbf{0 . 8 1 6}$ & 0.700 & $\mathbf{0 . 6 3 2}$ & 1.504 & $\mathbf{0 . 8 7 2}$ \\
\hline$\# 2$ & H-10 Al & 30 & 0.379 & $\mathbf{0 . 8 0 0}$ & 0.795 & $\mathbf{0 . 7 1 8}$ & 1.473 & $\mathbf{0 . 8 5 4}$ \\
$\# 6$ & $\mathrm{H}-50 \mathrm{Al}$ & 30 & 0.426 & $\mathbf{0 . 8 9 9}$ & 0.831 & $\mathbf{0 . 7 5 0}$ & 1.531 & $\mathbf{0 . 8 8 8}$ \\
$\# 10$ & $\mathrm{H}-95 \mathrm{Al}$ & 30 & 0.424 & $\mathbf{0 . 8 9 3}$ & 0.959 & $\mathbf{0 . 8 6 6}$ & 1.507 & $\mathbf{0 . 8 7 4}$ \\
$\# 15$ & Gran $17 \mathrm{Mg}$ & 30 & 0.431 & $\mathbf{0 . 9 0 8}$ & 0.877 & $\mathbf{0 . 7 9 2}$ & N.A. & $\mathbf{N . A .}$ \\
$\# 18$ & Glass beads & 30 & 0.465 & $\mathbf{0 . 9 8 0}$ & 1.088 & $\mathbf{0 . 9 8 3}$ & 1.951 & $\mathbf{1 . 1 3 1}$ \\
\hline$\# 3$ & H-10 Al & 40 & 0.464 & $\mathbf{0 . 9 7 8}$ & 0.753 & $\mathbf{0 . 6 8 0}$ & 1.377 & $\mathbf{0 . 7 9 8}$ \\
$\# 7$ & $\mathrm{H}-50 \mathrm{Al}$ & 40 & 0.436 & $\mathbf{0 . 9 1 9}$ & 0.782 & $\mathbf{0 . 7 0 6}$ & 1.436 & $\mathbf{0 . 8 3 2}$ \\
$\# 8$ & $\mathrm{H}-50 \mathrm{Al}$ & 40 & 0.398 & $\mathbf{0 . 8 4 0}$ & 0.955 & $\mathbf{0 . 8 6 2}$ & 1.333 & $\mathbf{0 . 7 7 3}$ \\
$\# 11$ & $\mathrm{H}-95 \mathrm{Al}$ & 40 & 0.461 & $\mathbf{0 . 9 7 2}$ & 0.727 & $\mathbf{0 . 6 5 7}$ & 1.475 & $\mathbf{0 . 8 5 5}$ \\
$\# 16$ & Gran $17 \mathrm{Mg}$ & 40 & 0.452 & $\mathbf{0 . 9 5 3}$ & 0.887 & $\mathbf{0 . 8 0 1}$ & N.A. & N.A. \\
\hline$\# 12$ & H-95 Al & 50 & 0.458 & $\mathbf{0 . 9 6 5}$ & 0.859 & $\mathbf{0 . 7 7 6}$ & 1.436 & $\mathbf{0 . 8 3 2}$ \\
$\# 19$ & Glass beads & 50 & 0.617 & $\mathbf{1 . 3 0 1}$ & 1.232 & $\mathbf{1 . 1 1 3}$ & 2.124 & $\mathbf{1 . 2 3 1}$ \\
\hline
\end{tabular}


Table 5 Absolute peak overpressure $\left(\Delta P_{\mathrm{s}}\right)$ values extracted from the pressure gauge at 2.0 from the charge for all the trials tested

\begin{tabular}{rrrrrr}
\hline Trial & Material & wt $\%$ & Mean particle size $(\mu \mathrm{m})$ & $\Delta P_{\mathrm{s}}(2.0 \mathrm{~m}-$ gauge $(\mathrm{kPa}))$ & $\boldsymbol{\Delta} \boldsymbol{P}_{\mathrm{s}} / \boldsymbol{\Delta} \boldsymbol{P}_{\mathrm{s}-\text { baseline }}$ \\
\hline$\# 0$ & Baseline & - & & - & $\mathbf{1 . 0 0 0}$ \\
\hline$\# 1$ & H-10 Al & 10 & 13 & 220.1 & $\mathbf{1 . 0 2 3}$ \\
$\# \mathbf{2}$ & H-10 Al & $\mathbf{3 0}$ & $\mathbf{1 3}$ & $\mathbf{3 2 2 . 9}$ & $\mathbf{1 . 4 6 7}$ \\
$\# 3$ & H-10 Al & 40 & 13 & 250.5 & $\mathbf{1 . 1 3 8}$ \\
\hline$\# 4$ & H-50 Al & 10 & 54 & $\mathbf{0 . 6 8 4}$ \\
$\# 5$ & H-50 Al & 20 & 54 & 339.6 & $\mathbf{1 . 5 4 3}$ \\
$\# \mathbf{6}$ & H-50 Al & $\mathbf{3 0}$ & $\mathbf{5 4}$ & $\mathbf{3 6 3 . 1}$ & $\mathbf{1 . 6 5 0}$ \\
$\# 7$ & H-50 Al & 40 & 54 & 282.1 & $\mathbf{1 . 2 8 2}$ \\
$\# 8$ & H-50 Al & 40 & 54 & 233.3 & $\mathbf{1 . 0 6 0}$ \\
\hline$\# 9$ & H-95 Al & 10 & 114 & 243.6 & $\mathbf{1 . 1 0 7}$ \\
$\# 10$ & H-95 Al & 30 & 114 & 339 & $\mathbf{1 . 5 4 0}$ \\
$\# \mathbf{1 1}$ & H-95 Al & $\mathbf{4 0}$ & $\mathbf{1 1 4}$ & $\mathbf{3 4 7 . 6}$ & $\mathbf{1 . 5 7 9}$ \\
$\# 12$ & H-95 Al & 50 & 114 & 233.8 & $\mathbf{1 . 0 6 2}$ \\
\hline$\# 13$ & Gran 17 Mg & 10 & 240 & 249.9 & $\mathbf{1 . 1 3 5}$ \\
$\# 14$ & Gran 17 Mg & $\mathbf{2 0}$ & $\mathbf{2 4 0}$ & $\mathbf{4 1 5 . 4}$ & $\mathbf{1 . 8 8 7}$ \\
$\# 15$ & Gran 17 Mg & 30 & 240 & N.A. & N.A. \\
$\# 16$ & Gran 17 Mg & 40 & 240 & N.A. & N.A. \\
\hline$\# 17$ & Glass beads & 10 & 66 & 183.3 & $\mathbf{0 . 8 3 3}$ \\
$\# 18$ & Glass beads & 30 & 66 & 191.3 & $\mathbf{0 . 8 6 9}$ \\
$\# 19$ & Glass beads & $\mathbf{5 0}$ & $\mathbf{6 6}$ & & $\mathbf{0 . 7 2 6}$ \\
\hline
\end{tabular}

Normalized peak overpressure values by the peak overpressure value of the baseline referred as normalized $\Delta P_{\mathrm{s}} / \Delta P_{\mathrm{s} \text {-baseline }}$ are also calculated. For every type of particles, the most efficient trial at enhancing (resp. mitigating) the peak blast overpressure is in red (resp. blue). The peak overpressure obtained for the trial \#4 (10\% H-50) is not considered as reliable

Table 6 Same as Table 5 but reordered for direct comparison at a specific particle mass fraction

\begin{tabular}{cccccc}
\hline Trial & Material & wt $\%$ & Mean particle size $(\mu \mathrm{m})$ & $\Delta P_{\mathrm{s}}(2.0 \mathrm{~m}-$ gauge $(\mathrm{kPa}))$ & $\boldsymbol{\Delta} \boldsymbol{P}_{\mathrm{s}} / \boldsymbol{\Delta} \boldsymbol{P}_{\mathrm{s}-\text { baseline }}$ \\
\hline$\# 0$ & Baseline & - & - & 220.1 & $\mathbf{1 . 0 0 0}$ \\
\hline$\# 1$ & H-10 Al & 10 & 13 & 225.2 & $\mathbf{1 . 0 2 3}$ \\
$\# 4$ & H-50 Al & 10 & 54 & $150.5($ not reliable $)$ & $\mathbf{0 . 6 8 4}$ \\
$\# 9$ & H-95 Al & 10 & 114 & 243.6 & $\mathbf{1 . 1 0 7}$ \\
$\# \mathbf{1 3}$ & Gran 17 Mg & $\mathbf{1 0}$ & $\mathbf{2 4 0}$ & $\mathbf{2 4 9 . 9}$ & $\mathbf{1 . 1 3 5}$ \\
$\# 17$ & Glass beads & 10 & 66 & 183.3 & $\mathbf{0 . 8 3 3}$ \\
\hline$\# 5$ & H-50 Al & 20 & 54 & 339.6 & $\mathbf{1 . 5 4 3}$ \\
$\# \mathbf{1 4}$ & Gran 17 Mg & $\mathbf{2 0}$ & $\mathbf{2 4 0}$ & $\mathbf{4 1 5 . 4}$ & $\mathbf{1 . 8 8 7}$ \\
\hline$\# 2$ & H-10 Al & 30 & 13 & 322.9 & $\mathbf{1 . 4 6 7}$ \\
$\# \mathbf{6}$ & H-50 Al & $\mathbf{3 0}$ & $\mathbf{5 4}$ & $\mathbf{3 6 3 . 1}$ & $\mathbf{1 . 6 5 0}$ \\
$\# 10$ & H-95 Al & 30 & 114 & 339 & $\mathbf{1 . 5 4 0}$ \\
$\# 15$ & Gran 17 Mg & 30 & 240 & N.A. \\
$\# 18$ & Glass beads & 30 & 66 & 191.3 & $\mathbf{0 . 8 6 9}$ \\
\hline$\# 3$ & H-10 Al & 40 & 13 & 250.5 & $\mathbf{1 . 1 3 8}$ \\
$\# 7$ & H-50 Al & 40 & 54 & 282.1 & $\mathbf{1 . 2 8 2}$ \\
$\# 8$ & H-50 Al & 40 & 54 & 233.3 & $\mathbf{1 . 0 6 0}$ \\
$\# 11$ & H-95 Al & $\mathbf{4 0}$ & $\mathbf{1 1 4}$ & $\mathbf{3 4 7 . 6}$ & $\mathbf{1 . 5 7 9}$ \\
$\# 16$ & Gran 17 Mg & 40 & 240 & N.A. & $\mathbf{N . A . ~}$ \\
\hline$\# \mathbf{1 2}$ & H-95 Al & $\mathbf{5 0}$ & $\mathbf{1 1 4}$ & $\mathbf{2 3 3 . 8}$ & $\mathbf{1 . 0 6 2}$ \\
$\# \mathbf{1 9}$ & Glass beads & $\mathbf{5 0}$ & $\mathbf{6 6}$ & $\mathbf{1 5 9 . 7}$ & $\mathbf{0 . 7 2 6}$ \\
\hline
\end{tabular}


Table 7 Comparison between peak overpressures at 2.0 from the charge obtained through videography or with pressure gauge measurements

\begin{tabular}{|c|c|c|c|c|c|c|}
\hline Trial & Material & $\mathrm{wt} \%$ & Mean particle size $(\mu \mathrm{m})$ & $\Delta P_{\mathrm{S}}(2.0 \mathrm{~m}-\operatorname{video}(\mathrm{kPa}))$ & $\Delta P_{\mathrm{s}}(2.0 \mathrm{~m}-$ gauge $(\mathrm{kPa}))$ & R.E. (\%) \\
\hline$\# 0$ & Baseline & - & - & 276.2 (extp) & 220.1 & 25.5 \\
\hline$\# 1$ & $\mathrm{H}-10 \mathrm{Al}$ & 10 & 13 & $320.3($ extp) & $225.2(\mathrm{sd})$ & 42.2 \\
\hline \#2 & $\mathrm{H}-10 \mathrm{Al}$ & 30 & 13 & $311.0(\operatorname{extp})$ & 322.9 & -3.7 \\
\hline$\# 3$ & $\mathrm{H}-10 \mathrm{Al}$ & 40 & 13 & 335.4 (extp) & $250.5(\mathrm{sd})$ & 33.9 \\
\hline$\# 4$ & $\mathrm{H}-50 \mathrm{Al}$ & 10 & 54 & 288.5 & 150.5 (id - (not reliable) $)$ & 91.7 \\
\hline$\# 5$ & $\mathrm{H}-50 \mathrm{Al}$ & 20 & 54 & 313.0 (extp) & 339.6 & -7.8 \\
\hline \#6 & $\mathrm{H}-50 \mathrm{Al}$ & 30 & 54 & $273.5($ extp) & 363.1 & -24.7 \\
\hline$\# 7$ & $\mathrm{H}-50 \mathrm{Al}$ & 40 & 54 & 285.8 (extp) & $282.1(\mathrm{sd})$ & 1.3 \\
\hline$\# 8$ & $\mathrm{H}-50 \mathrm{Al}$ & 40 & 54 & 316.8 (extp) & $233.3(\mathrm{sd})$ & 35.8 \\
\hline$\# 9$ & $\mathrm{H}-95 \mathrm{Al}$ & 10 & 114 & $280.5($ extp $)$ & 243.6 & 15.1 \\
\hline$\# 10$ & $\mathrm{H}-95 \mathrm{Al}$ & 30 & 114 & 308.1 (extp) & $339.0(\mathrm{sd})$ & -9.1 \\
\hline$\# 11$ & $\mathrm{H}-95 \mathrm{Al}$ & 40 & 114 & 307.5 & 347.6 & -11.5 \\
\hline$\# 12$ & $\mathrm{H}-95 \mathrm{Al}$ & 50 & 114 & 281.9 (extp) & 233.8 & 20.6 \\
\hline$\# 13$ & Gran $17 \mathrm{Mg}$ & 10 & 240 & $296.3($ extp) & 249.9 & 18.6 \\
\hline$\# 14$ & Gran $17 \mathrm{Mg}$ & 20 & 240 & 267.6 (extp) & $415.4(\mathrm{sd})$ & -35.6 \\
\hline$\# 15$ & Gran $17 \mathrm{Mg}$ & 30 & 240 & 278.2 (extp) & N.A. & N.A. \\
\hline$\# 16$ & Gran $17 \mathrm{Mg}$ & 40 & 240 & 325.6 (extp) & N.A. & N.A. \\
\hline$\# 17$ & Glass beads & 10 & 66 & 222.5 (extp) & $183.3(\mathrm{sd})$ & 21.4 \\
\hline$\# 18$ & Glass beads & 30 & 66 & 187.6 & 191.3 & -1.9 \\
\hline$\# 19$ & Glass beads & 50 & 66 & 164.3 & 159.7 & 2.9 \\
\hline
\end{tabular}

extp: peak overpressure values extrapolated by inferring the blast curvature as shown in Fig. 5, sd: overpressure profile presenting a slight deviation from the modified Friedlander form, id: overpressure profile presenting an important deviation from the modified Friedlander form, R.E.: relative error between the two methods

\section{Appendix}

Tables 3 and 4 present the times of arrival captured with the pressure gauges at all distances from the charge $(1.0$ $\mathrm{m}, 1.5 \mathrm{~m}$, and $2.0 \mathrm{~m})$. Table 3 is sorted by particle size, whereas Table 4 is sorted by mass fraction. The same tables, but for the peak blast overpressures obtained at $2.0 \mathrm{~m}$ from the charge, are shown in Tables 5 and 6 . These peak blast overpressures are compared with the peak overpressures obtained with the videography analysis at a distance of 2.0 from the charge in Table 7 . Note that most of the time the blast front was not visible at this distance, at the same height as the charge. Consequently, the blast front position at 2.0 $\mathrm{m}$ from the charge was extrapolated by inferring the blast curvature as shown in Fig. 5. Discarding the non-reliable peak overpressure recorded for trial \#4, the maximum discrepancy observed between the gauge measurements and the video analysis method is $42.2 \%$. However, the discrepancies between the two methods are not similar for all trials tested, suggesting that they are of a stochastic nature and not a systematic error resulting from the methodology employed. The discrepancies are explained by the fact that the blast is not tracked in the same directions around the charge (pressure gauges are not in the camera field of view as shown in Fig. 1). In other words, the blast propagation is not isotropic. Figure 19 exhibits the peak blast overpressure decays obtained with the videography in the mid-to-far field for trials with aluminum and magnesium particles. The peak overpressure decays are also plotted in Fig. 20a, c, e at three specific mass fractions $(10 \%, 30 \%$, and $40 \%)$ to illustrate the effect of the material and particle sizes. The normalized plots are also shown in Fig. 20b, d, f to highlight the performance. The trial videos corresponding to Figs. 7, 8, and 9 are available online as supplementary materials. 


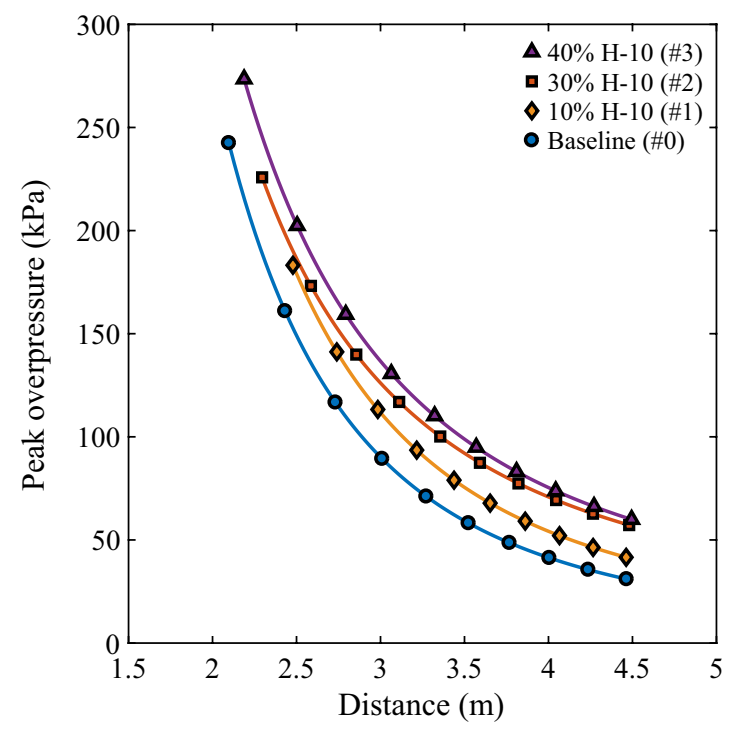

(a) $\mathrm{H}-10$

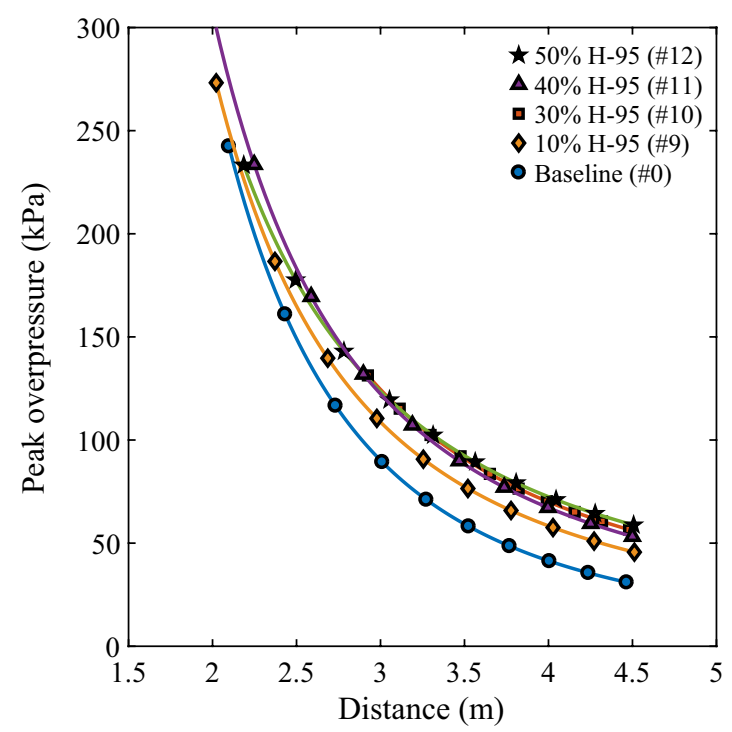

(c) $\mathrm{H}-95$

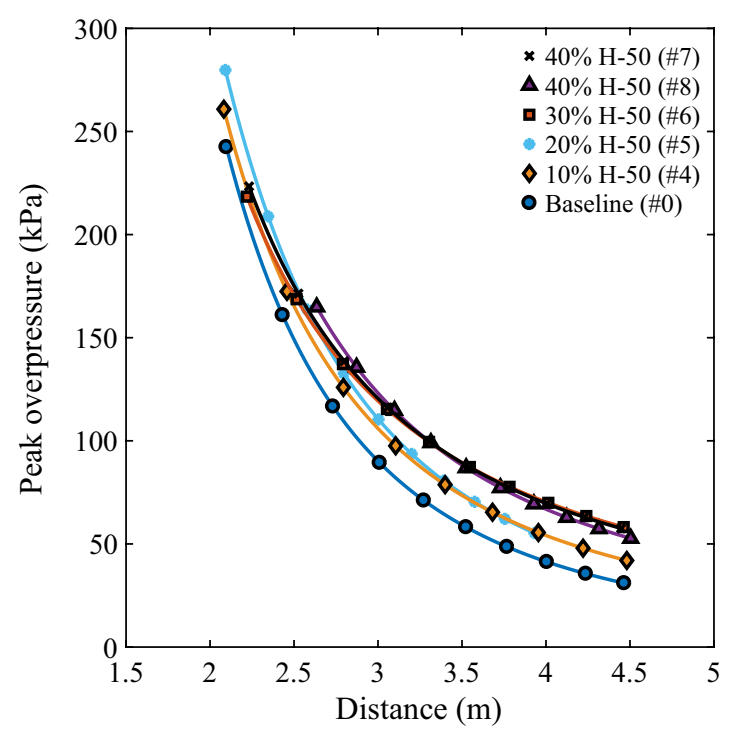

(b) $\mathrm{H}-50$

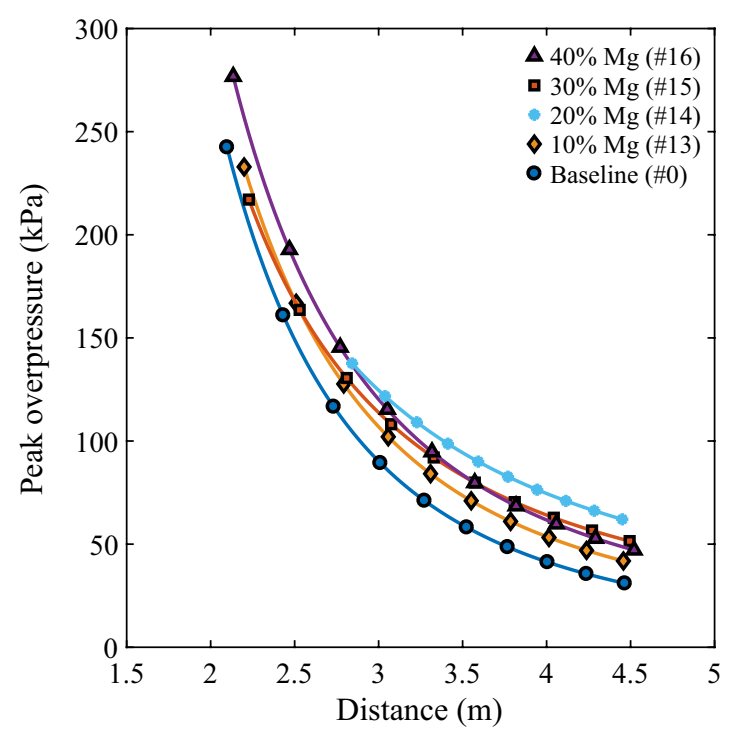

(d) $\mathrm{Mg}$

Fig. 19 Peak blast overpressure decays plotted in the mid-to-far field for trials with a H-10 Al, b H-50 Al, c H-95 Al, and d Gran $17 \mathrm{Mg}$ 


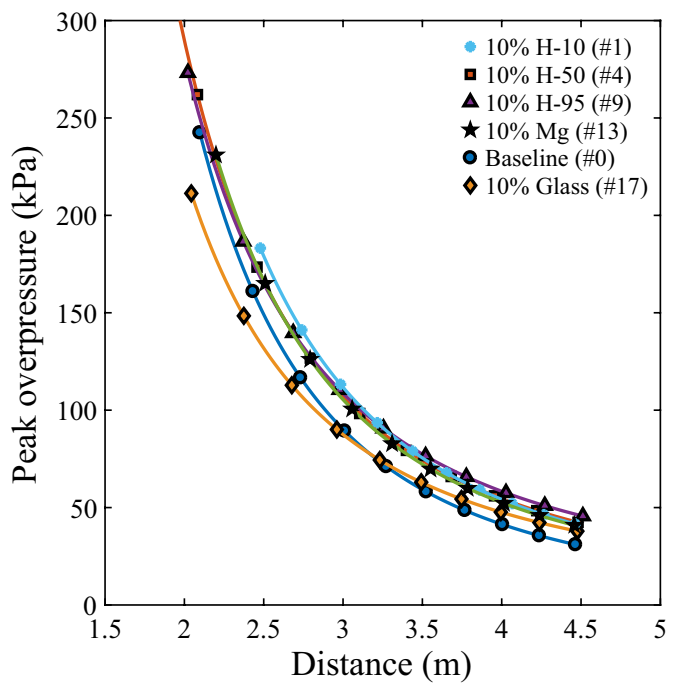

(a) $10 \mathrm{wt} \%$

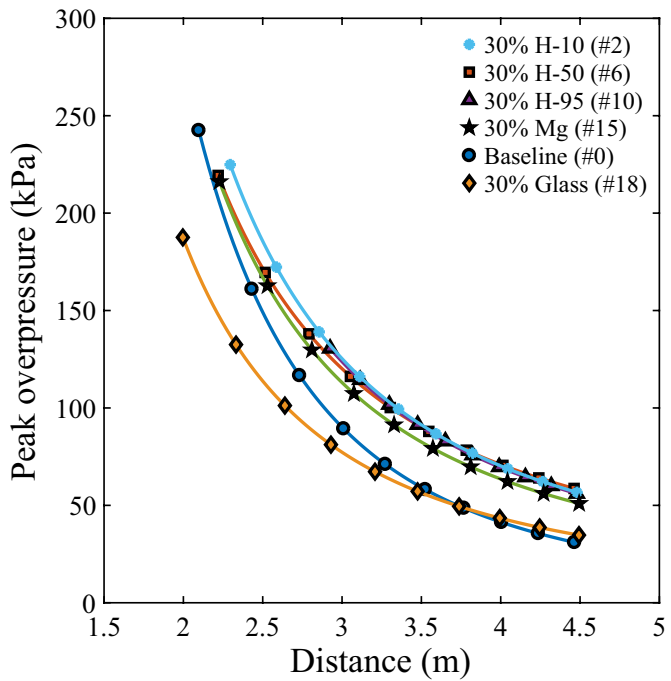

(c) $30 \mathrm{wt} \%$

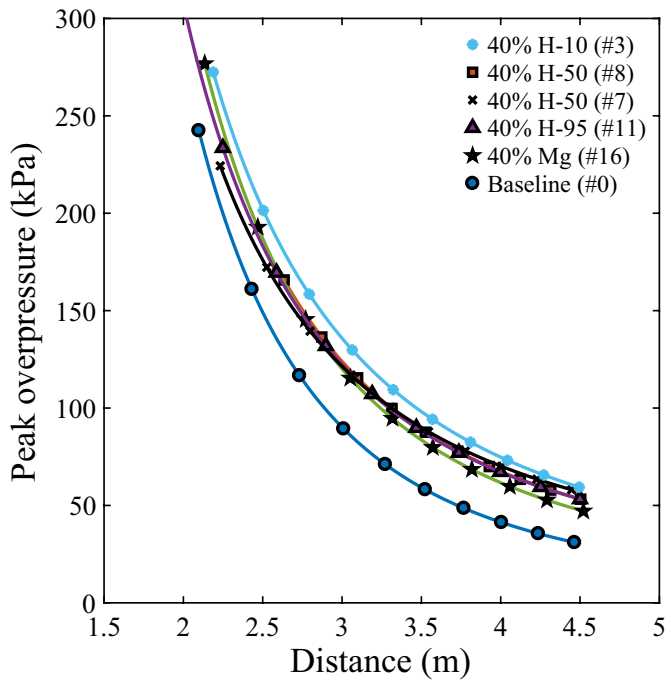

(e) $40 \mathrm{wt} \%$

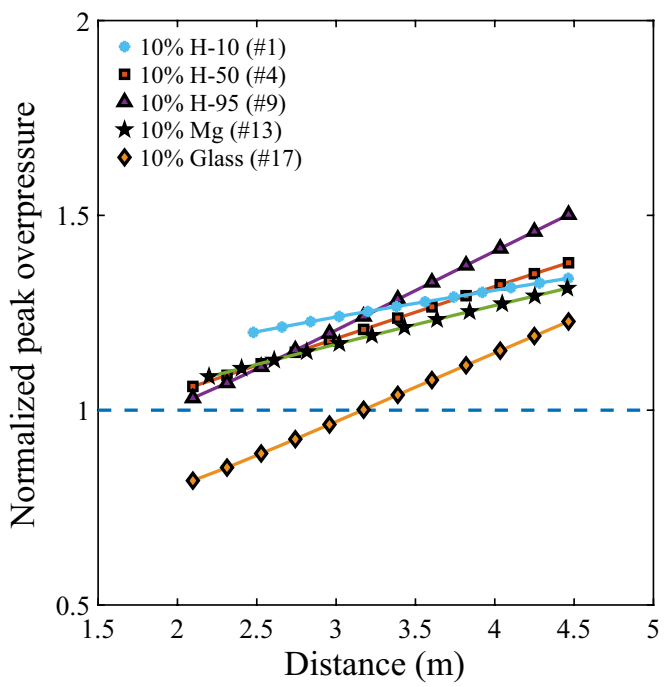

(b) $10 \mathrm{wt} \%$

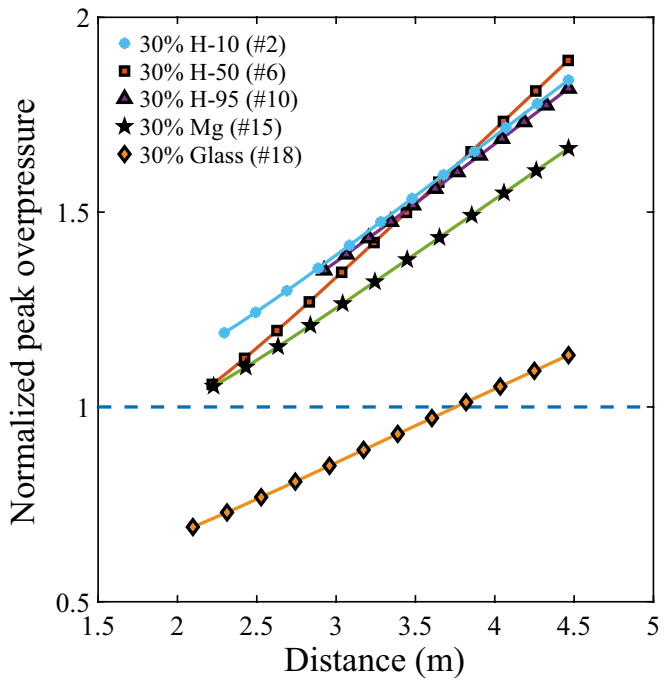

(d) $30 \mathrm{wt} \%$

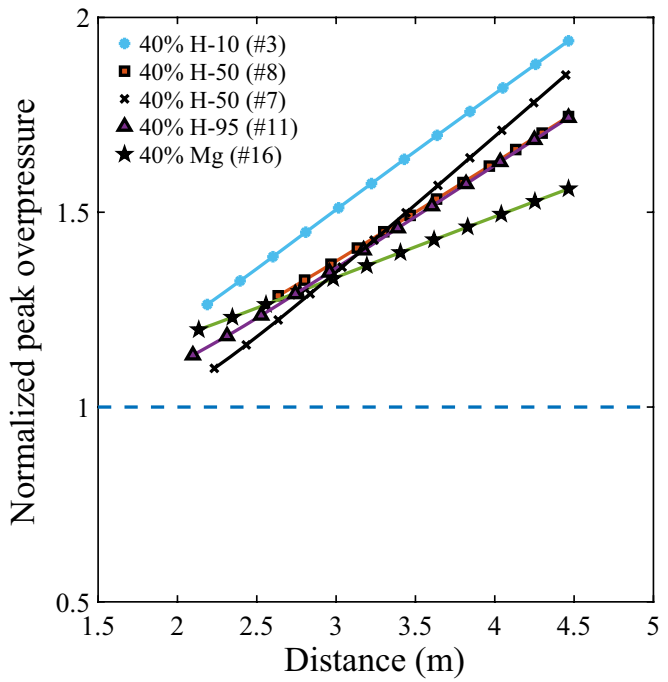

(f) $40 \mathrm{wt} \%$ 
4Fig. 20 Effect of particle material and particle sizes on the peak blast overpressure decays with dimensional distance, for particle mass fractions of $10 \mathrm{wt} \%, 30 \mathrm{wt} \%$, and $40 \mathrm{wt} \%$

Acknowledgements The authors thank the field operation team at DRDC Suffield for assistance with setting up the experimental test site and S. Trebble for carrying out the high-speed video recording. The authors would like to thank A. Longbottom and A. Milne at Fluid Gravity Engineering for their valuable comments on the pressure gauge analysis. The authors would also like to thank the four anonymous reviewers for their many constructive comments.

\section{Compliance with ethical standards}

Conflict of Interest The authors declare that they have no conflict of interest.

Open Access This article is licensed under a Creative Commons Attribution 4.0 International License, which permits use, sharing, adaptation, distribution and reproduction in any medium or format, as long as you give appropriate credit to the original author(s) and the source, provide a link to the Creative Commons licence, and indicate if changes were made. The images or other third party material in this article are included in the article's Creative Commons licence, unless indicated otherwise in a credit line to the material. If material is not included in the article's Creative Commons licence and your intended use is not permitted by statutory regulation or exceeds the permitted use, you will need to obtain permission directly from the copyright holder. To view a copy of this licence, visit http://creativecommons.org/licenses/by/4.0/.

\section{References}

1. Escales, R.: UK24377 (1899)

2. Roth, G.: Performance of explosives (1900)

3. Yen, N.H., Wang, L.Y.: Reactive metals in explosives. Propellants Explos. Pyrotech. 37(2), 143-155 (2012). https://doi.org/10.1002/ prep. 200900050

4. Frost, D.L., Zhang, F.: The nature of heterogeneous blast explosives. 19th International Symposium on Military Aspects of Blast and Shock (MABS 19), Calgary, Canada (2006)

5. Trzciński, W.A., Maiz, L.: Thermobaric and enhanced blast explosives-properties and testing methods. Propellants Explos. Pyrotech. 40(5), 632-644 (2015). https://doi.org/10.1002/ prep. 201400281

6. Türker, L.: Thermobaric and enhanced blast explosives (TBX and EBX). Def. Technol. 12(6), 423-445 (2016). https://doi.org/ 10.1016/j.dt.2016.09.002

7. Vadhe, P.P., Pawar, R.B., Sinha, R.K., Asthana, S.N., Subhananda Rao, A.: Cast aluminized explosives (review). Combust. Explos. Shock Waves 44(4), 461-477 (2008). https://doi.org/10.1007/ s10573-008-0073-2

8. Capellos, C., Baker, E.L., Nicolich, S., Balas, W., Pincay, J., Stiel, L.I.: Eigenvalue detonation of combined effects aluminized explosives. AIP Conf. Proc. 955(2007), 357-360. https://doi.org/10. $1063 / 1.2833055$

9. Frost, D.L.: Heterogeneous/particle-laden blast waves. Shock Waves 28(3), 439-449 (2018). https://doi.org/10.1007/ s00193-018-0825-1

10. Pontalier, Q., Loiseau, J., Goroshin, S., Frost, D.L.: Experimental investigation of blast mitigation and particle-blast interaction during the explosive dispersal of particles and liquids.
Shock Waves 28(3), 489-511 (2018). https://doi.org/10.1007/ s00193-018-0821-5

11. Pontalier, Q., Lhoumeau, M., Milne, A., Longbottom, A., Frost, D.L.: Numerical investigation of particle-blast interaction during explosive dispersal of liquids and particles. Shock Waves 28(3), 513-531 (2018). https://doi.org/10.1007/s00193-018-0820-6

12. Pontalier, Q., Lhoumeau, M., Frost, D.L.: Blast wave mitigation in granular materials. AIP Conf. Proc. 1979(1), 110014 (2018). https://doi.org/10.1063/1.5044933

13. Loiseau, J., Pontalier, Q., Milne, A., Goroshin, S., Frost, D.L.: Terminal velocity of liquids and granular materials accelerated by a high explosive. Shock Waves 28(3), 473-487 (2018). https:// doi.org/10.1007/s00193-018-0822-4

14. Ripley, R .C., Zhang, F., Lien, F.-S.: Acceleration and heating of metal particles in condensed matter detonation. Proc. R. Soc. Lond. A 468(February), 1564-1590 (2012). https://doi.org/10. 1098/rspa.2011.0595

15. Peuker, J.M., Krier, H., Glumac, N.: Particle size and gas environment effects on blast and overpressure enhancement in aluminized explosives. Proc. Combust. Inst. 34(2), 2205-2212 (2013). https:// doi.org/10.1016/j.proci.2012.05.069

16. Zarei, Z., Frost, D.L.: Simplified modeling of blast waves from metalized heterogeneous explosives. Shock Waves 21(5), 425-438 (2011). https://doi.org/10.1007/s00193-011-0316-0

17. Balakrishnan, K., Menon, S.: On the role of ambient reactive particles in the mixing and afterburn behind explosive blast waves. Combust. Sci. Technol. 182(2), 186-214 (2010). https://doi.org/ 10.1080/00102200903341579

18. McNesby, K.L., Homan, B.E., Ritter, J.J., Quine, Z., Ehlers, R.Z., McAndrew, B.A.: Afterburn ignition delay and shock augmentation in fuel rich solid explosives. Propellants Explos. Pyrotech. 35(1), 57-65 (2010). https://doi.org/10.1002/prep.200800084

19. Duan, J., Wu, C., An, F.J., Liao, S.S.: A quasi-analytical model of aluminized explosive products under strong constraint. Adv. Mech. Eng. 9(11), 1-10 (2017). https://doi.org/10.1177/16878 14017739511

20. Yuan, X., Wu, C., An, F., Liao, S., Zhou, M., Shi, Z., Xue, D.: A non-isentropic model of aluminized explosives involved with the reaction degree of aluminum powder for post-detonation burning behavior. Phys. Fluids 32, 023306 (2020). https://doi.org/10. $1063 / 1.5139692$

21. Li, X., Pei, H., Zhang, X., Zheng, X.: Effect of aluminum particle size on the performance of aluminized explosives. Propellants Explos. Pyrotech. 45(5), 807-813 (2020). https://doi.org/10.1002/ prep. 201900308

22. Lefrancois, A., Baudin, G., Le Gallic, C., Boyce, P., Coudoing, J-P.: Nanometric aluminum powder influence on the detonation efficiency of explosives. 12th International Detonation Symposium, San Diego, U.S.A. (2002)

23. Manner, V.W., Pemberton, S.J., Gunderson, J.A., Herrera, T.J., Lloyd, J.M., Salazar, P.J., Rae, P., Tappan, B.C.: The role of aluminum in the detonation and post-detonation expansion of selected cast HMX-based explosives. Propellants Explos., Pyrotech. 37(2), 198-206 (2012). https://doi.org/10.1002/prep.20110 0138

24. Makhov, M.N., Gogulya, M.F., Dolgoborodov, A.Yu., Brazhnikov, M.A., Arkhipov, V.I., Pepekin, V.I.: Acceleration ability and heat of explosive decomposition of aluminized explosives. Combust. Explos. Shock Waves 40(4), 458-466 (2004). https://doi.org/10. 1023/B:CESW.0000033569.77449.d9

25. Tappan, B.C., Hill, L.G., Manner, V.W., Pemberton, S.J., Lieber, M.A., Johnson, C.E., Sanders, V.E.: Reactions of powdered aluminum with explosives that selectively form carbon dioxide or water as oxidizers. Int. J. Energ. Mater. Chem. Propuls. 15(4), 339-350 (2016). https://doi.org/10.1615/IntJEnergeticMateria 1sChemProp.2017011503 
26. Robbins, D.L., Anderson, E.K., Anderson, M.U., Jackson, S.I., Short, M.: Cylinder test characterization of an ammonium nitrate and aluminum powder explosive. 15th International Symposium on Detonation, vol. 803, pp. 826-835 (2014)

27. Baudin, G., Lefrancois, A., Bergues, D., Bigot, J., Champion, Y.: Combustion of nanophase aluminum in the detonation products of nitromethane and TNT. 11th International Detonation Symposium, Colorado, U.S.A. (1998)

28. Loiseau, J., Goroshin, S., Frost, D.L., Higgins, A.J., Zhang, F.: Ability of metalized gelled nitromethane to accelerate a flyer plate. 16th International Detonation Symposium, Cambridge, U.S.A. (2018)

29. Kato, Y., Murata, K., Itoh, S.: Detonation characteristics of packed beds of aluminum saturated with nitromethane. 13th International Detonation Symposium, IDS 2006, pp. 187-195 (2006)

30. Schmitt, M.M., Bowden, P.R., Tappan, B.C., Henneke, D.: Steadystate shock-driven reactions in mixtures of nano-sized aluminum and dilute hydrogen peroxide. J. Energ. Mater. 36(3), 266-277 (2018). https://doi.org/10.1080/07370652.2017.1376233

31. Loiseau, J., Chase, G., Goroshin, S., Frost, D.L.: Detonation and metal acceleration of aluminum-water mixtures. 16th International Detonation Symposium, Cambridge, U.S.A. (2018)

32. Beckstead, M.W.: Correlating aluminum burning times. Combust. Explos. Shock Waves 41(5), 533-546 (2005). https://doi.org/10. 1007/s10573-005-0067-2

33. Brousseau, P., Dorsett, H.E., Cliff, M.D., Anderson, C.J.: Detonation properties of explosives containing nanometric aluminum powder. 12th Internation Detonation Symposium, pp. 1-10, San Diego, U.S.A. (2002)

34. Maiz, L., Trzciński, W.A.: Detonation and combustion of new heterogeneous composite explosives containing aluminum particles. 11th International Armament Conference on Scientific Aspects of Armament and Safety Technology, Ryn, Poland (2016)

35. Frost, D.L., Zhang, F., Murray, S., McCahan, S.: Critical conditions for ignition of metal particles in a condensed explosive. 12th International Detonation Symposium, pp. 1-10 (2002)

36. Trzciński, W.A., Paszula, J., Grys, S.: Detonation and blast wave characteristics of nitromethane mixed with particles of an aluminium-magnesium alloy. Propellants Explos. Pyrotech. 35(2), 85-92 (2010). https://doi.org/10.1002/prep.200900041

37. Dewey, J.M.: The shape of the blast wave: studies of the Friedlander equation. 21st International Symposium on Military Aspects of Blast and Shock (MABS 21), pp. 1-9, Jerusalem, Israel (2010)

38. Kleine, H., Dewey, J.M., Ohashi, K., Mizukaki, T., Takayama, K.: Studies of the TNT equivalence of silver azide charges.
Shock Waves 13(2), 123-138 (2003). https://doi.org/10.1007/ s00193-003-0204-3

39. Fried, L.E., Howard, W.M., Souers, P.C.: Cheetah 2.0 user's manual. Technical report, Lawrence Livermore National Laboratory, Livermore, CA, USA (1998)

40. Keshavarz, M.H.: Detonation temperature of high explosives from structural parameters. J. Hazard. Mater. 137(3), 1303-1308 (2006). https://doi.org/10.1016/j.jhazmat.2006.04.057

41. Tanguay, V., Goroshin, S., Higgins, A.J., Zhang, F.: Aluminum particle combustion in high-speed detonation products. Combust. Sci. Technol. 181(4), 670-693 (2009). https://doi.org/10.1080/ 00102200802643430

42. Weingärtner, H., Franck, E.U.: Supercritical water as a solvent. Angew. Chem. Int. Ed. 44(18), 2672-2692 (2005). https://doi.org/ 10.1002/anie. 200462468

43. Holley, C.E., Huber, E.J.: The heats of combustion of magnesium and aluminum. J. Am. Chem. Soc. 73(12), 5577-5579 (1951). https://doi.org/10.1021/ja01156a020

44. Persson, P.-A., Holmberg, R., Lee, J.: Rock Blasting and Explosives Engineering. CRC Press, Boca Raton (1993)

45. Baker, W.E.: Explosions in Air. University of Texas Press, Austin (1973)

46. Kinney, G.F., Graham, K.J.: Explosive Shocks in Air, 2nd edn. Springer, Berlin (1985)

47. Bach, G.G., Lee, J.H.S.: An analytical solution for blast waves. AIAA J. 8(2), 271-275 (1970). https://doi.org/10.2514/3.5655

48. Dobratz, B.M., Crawford, P.C.: LLNL explosives handbookproperties of chemical explosives and explosive simulants. Technical report, Lawrence Livermore National Laboratory (LLNL), Livermore, California (1985)

49. Leadbetter, J., Ripley, R.C., Zhang, F., Frost, D.L.: Multiple energy scaling of blast waves from heterogeneous explosives. 21st International Colloquium on the Dynamics of Explosions and Reactive Systems (ICDERS), Poitiers, France (2007)

50. Pontalier, Q., Longbottom, A., Cargill, S., Grapes, C., Loiseau, J., Goroshin, S., Frost, D.L., Zhang, F.: Numerical investigation of blast enhancement with metalized explosives. 32nd International Symposium on Shock Waves, pp. 1-13, Singapore (2019). https:// doi.org/10.3850/978-981-11-2730-4_0323-cd

Publisher's Note Springer Nature remains neutral with regard to jurisdictional claims in published maps and institutional affiliations. 